\title{
Review
}

\section{Biosynthesis and extraction of high-value carotenoid from algae}

\author{
Amit Kumar Gupta ${ }^{1}$, Kunal Seth ${ }^{2}$, Kirti Maheshwari ${ }^{1}$, Prabhat Kumar Baroliya ${ }^{3}$, Mukesh Meena ${ }^{1}$, \\ Ashwani Kumar ${ }^{4, *}$, Vandana Vinayak ${ }^{5}$, Harish ${ }^{1, *}$ (1) \\ ${ }^{1}$ Department of Botany, Mohanlal Sukhadia University, 313001 Udaipur, Rajasthan, India, ${ }^{2}$ Department of Botany, \\ Government Science College, Pardi, 396125 Valsad, Gujarat, India, ${ }^{3}$ Department of Chemistry, Mohanlal Sukhadia \\ University, 313001 Udaipur, Rajasthan, India, ${ }^{4}$ Metagenomics and Secretomics Research Laboratory, Department of \\ Botany, Dr. Harisingh Gour Central University, 470003 Sagar, MP, India, ${ }^{5}$ Diatom Nanoengineering and Metabolism \\ Laboratory (DNM), School of Applied Sciences, Dr. Harisingh Gour Central University, 470003 Sagar, MP, India
}

\section{TABLE OF CONTENTS}

\author{
1. Abstract \\ 2. Introduction \\ 3. Carotenoid biosynthesis pathways in algae \\ 4. Chemistry of different carotenoid \\ 5. Extraction of high value carotenoids \\ 6. Application of carotenoids \\ 7. Global carotenoid market \\ 8. Concluding remarks \\ 9. Author contributions \\ 10. Ethics approval and consent to participate \\ 11. Acknowledgment \\ 12. Funding \\ 13. Conflict of interest \\ 14. References
}

\section{Abstract}

Algae possess a considerable potential as biorefinery for the scale-up production of high-value natural compounds like - carotenoids. Carotenoids are accessory pigments in the light-harvesting apparatus and also act as antioxidants and photo-protectors in green cells. They play important roles for humans, like-precursors of vitamin A, reduce the risk of some cancers, helps in the prevention of age-related diseases, cardiovascular diseases, improve skin health, and stimulates immunity. To date, about 850 types of natural carotenoid compounds have been reported and they have approximated 1.8 billion US\$ of global market value. In comparison to land plants, there are few reports on biosynthetic pathways and molecular level regulation of algal carotenogenesis. Recent advances of algal genome sequencing, data created by high-throughput technologies and transcriptome studies, enables a better understanding of the origin and evolution of de novo carotenoid biosynthesis pathways in algae. Here in this review, we focused on, the biochemical and molecular mechanism of carotenoid biosynthesis in algae. Additionally, struc- tural features of different carotenoids are elaborated from a chemistry point of view. Furthermore, current understandings of the techniques designed for pigment extraction from algae are reviewed. In the last section, applications of different carotenoids are elucidated and the growth potential of the global market value of carotenoids are also discussed.

\section{Introduction}

Carotenoids comprehend a group of naturally occurring lipophilic (fat-soluble) pigments. $\mathrm{C}_{40}$ carbon atoms with varying numbers of the double bond (polyene backbone) interlink and forms the basic structure of the carotenoid molecule, resulting from the isoprenoid pathway [1, 2]. The discovery of carotenoid has far been decoded the mystery behind the prismatic and radiant colors, we observe in fruits, vegetables, flowers, and leaves. They are also responsible for the flamboyant coloration in animals like flamingos, crustaceans, shells, and fish skin as in salmon [3]. In nature, all photosynthetic organisms (cyanobacteria, algae, higher plants), as well as some non- 
photosynthetic organisms such as fungi (Umbelopsis isabellina) and bacteria (Deinococcus-Thermus), have the capability of carotenoid biosynthesis [4, 5]. The sundry shades of colors in fruits and vegetables, while they undergo ripening as well as color change during metamorphosis of crab, are also because of carotenoid transitions [6]. From an aesthetic point of view, carotenoids augment the beauty of the environment by adding pigmentation to fruits and flowers, enhancing the taste of fruits, and adding aromas to the flower, which in turn fascinate pollinators and engross seed dispersal organisms.

About 850 kinds of carotenoids have been reported up to 2018 [7]. They are broadly grouped into two categories either on basis of functional properties or chemical structure. Functionally, they can be either primary having a vital role in photosynthesis or secondary having a role in stress conditions [8]. Based on chemical structure, carotenoids having pure carbon skeleton and are referred to as carotenes (cyclized or uncyclized, e.g., $\alpha$-carotene, $\beta$ carotene, $\gamma$-carotene, lycopene, phytoene) and another, the oxygenated carotenes, are known as xanthophylls. Lutein, zeaxanthin, astaxanthin, violaxanthin, canthaxanthin, echineone, $\beta$-cryptoxanthin, fucoxanthin, peridinin, neoxanthin are some of the well-known xanthophylls [9]. The presence of xanthophyll as fatty acid esters, glycosides, sulfates, and protein complexes have been reported [10]. Around 50 types of carotene and $\sim 800$ types of xanthophyll have been reported. Carotenoids with more than 45 or 50 carbon atoms are referred to as higher carotenoids, while, with less-than 40-carbon skeleton are known as apocarotenoids. About 40 types of higher carotenoids are reported in archaea and about 120 types of apocarotenoids are reported in higher plant and animals. Most carotenoids have a 40carbon skeleton [10]. Sweet potato, carrots, pumpkin, apricots, cantaloupe, spinach, and broccoli are a rich source of $\alpha$-carotene [11]. Lycopene is abundant in tomato, watermelon, pink grape fruit [12]. $\beta$-cryptoxanthin and zeaxanthin are found in peach, papaya, mandarin, orange, and tangerine [13]. Collards, butternut, raw spinach, corn are also enriched with zeaxanthin [14]. Lutein, violaxanthin, $\beta$-carotene, and neoxanthin are abundant in green leafy vegetables [15]. Crocin, crocetin, picrocrocin are the three apocarotenoids present in stigmata of Crocus flower which provide coloring properties to saffron [16].

Chloroplast-the green organ of photosynthetic tissue of higher plants, is not only the site of photosynthesis, but also plays an important role in biosynthesis and accumulation of carotenoid. Stanely and Yuan have reported many nuclei encoded membrane proteins, their synthesis in the cytoplasm as polypeptide precursor with amino terminus extension, directed to the chloroplast, for the biosynthesis of carotenoids [17]. The carotenogenesis pathway is under strict gene control and acts as a chemotaxonomic marker [18]. On the flip side, this pathway is equally prone to stress periods and affected by physical and envi- ronmental factors like salinity, temperature, irradiance, nutrition, and growth factors [19]. The foremost, premier, and rate-limiting step of the biosynthetic pathway is the condensation of two GGPP (Geranyl geranyl pyrophosphate), to originate phytoene (colorless carotenoid) in presence of PSY (Phytoene synthase) enzyme [20]. Subsequently, an array of sequential desaturations results in the production of all-trans lycopene. Major enzymes involved are Phytoene desaturase (PDS), $\zeta$-Carotene Isomerase (Z-ISO), $\zeta$-Carotene desaturase (ZDS), and Carotenoid isomerase (Crt-ISO). The colored sequence from phytoene is as follows: phytofluene (colorless), $\zeta$-carotene (green), neurosporene (orange/yellow), lycopene (red), and $\gamma$-carotene (orange). Lycopene then undergoes cyclization by Lycopene $\epsilon$-cyclase (LCY-E), and Lycopene $\beta$-cyclase (LCY$\mathrm{B})$, forming $\alpha$-carotene and $\beta$-carotene, respectively and this step is a critical branch point [21]. $\alpha$ - and $\beta$-carotene undergoes hydroxylation in presence of EHY ( $\epsilon$-carotene hydroxylase) and $\mathrm{BCH}$ ( $\beta$-carotene hydroxylase) to form lutein and zeaxanthin, respectively. $\beta$-Cryptoxanthin is an intermediate product during zeaxanthin formation. Antheraxanthin and violaxanthin are formed by epoxidation and de-epoxidation of zeaxanthin by ZEP (Zeaxanthin epoxidase) and VDE (Violaxanthin de-epoxidase), respectively, making up the xanthophyll cycle. In the cytoplasm, zeaxanthin may form adinoxanthin by BKT ( $\beta$-carotene ketolase) which in turn forms astaxanthin using the same enzyme by incorporation of additional keto group. BKT can also act as an intermediate enzyme to $\beta$-carotene by adding a keto group to it, resulting in the formation of echinenone and canthaxanthin as an intermediate. Neoxanthin synthase enzyme converts violaxanthin into 9-cis neoxanthin [22].

Carotenoids can be stored inside or outside the chloroplast according to their functional role. Primary pigments are stored inside while secondary pigments remain outside the chloroplast in lipid globules. Green tissue conserves the accumulation of carotenoids while the levels in non-green tissues may vary according to the developmental stage. Though, cell storage capacity, catabolism, and degradation rate may alter the carotenoid profile [20]. The phenomenal process of photosynthesis on the whole needs chlorophyll as a pre-dominant pigment, while carotenoids play a donative role in the overall mechanism of energy transport and conversion [23]. Carotenoids majorly play a dual role, primarily; they act as accessory lightharvesting pigments in photosystem, thereby extending the range of solar radiation (wavelength) which is not absorbed by chlorophyll and hence, drive the process of photosynthesis to a greater peak. Secondly, the noteworthy role of carotenoids is photo protective by dissipating extra energy and scavenging toxic oxygen molecules. In this way, carotenoids stabilize pigment-protein complexes; and maintain the integrity of membranes necessary for cell survival and development [24]. Secondary carotenoids like astaxanthin and canthaxanthin, accumulates in high amount 
in cytoplasmic lipid globules under stress conditions. Begum et al. [25] have reported, the presence of characteristic pink/red color of some stressed algae due to carotenoid accumulation as a protective layer. In non-photosynthetic bacterium (Deinococcus-Thermus) and fungi, carotenoid plays a proficient photo-protective role [26]. The overall stability and functionality of the photosynthetic apparatus can be attributed to the antioxidant property these pigments own, which can prevent photo-oxidative damage [27]. Another role of carotenoids is a requirement to form prolamellar bodies (PLB's) in etiolated seedlings to speed up photo-morphogenesis [27, 28]. Their role as a precursor of phytohormone ABA (abscisic acid) and SL (strigolactone) has been reported [29, 30]. Cazzonelli and Pogson have reported the role of $\beta$-ionone's (catabolism product of carotenoid) in plant-insect interaction [29].

Unlike higher plants and other conventional sources, algae have a small life cycle with a speedy growth, cover less area for cultivation purposes, and are more efficient at biomass production and therefore serve as a better source for carotenoid production that too in cost-effective way. Different algae have been explored and utilized for the production of different carotenoids, which are listed in Table 1 (Ref. [31-51]). In the next few sections of this paper, we have highlighted the biosynthesis pathway for different carotenoids with special reference to algae. Further chemical aspects, extraction of synthesized carotenoid and their application and global market scenario are also discussed.

\section{Carotenoid biosynthesis pathways in algae}

The basic carotenoid biosynthesis pathway seems to be the same in algae and streptophytes. Based on genome and transcriptome-wide studies, now it is clear that the evolution of carotenoid biosynthesis pathways in algae have involve various genetic mechanism like gene duplications, gene loss, gene transfer etc. Due to these genetic events, the carotenoid biosynthesis pathways in algae became more complex than that of terrestrial plants [52]. The biochemical and molecular mechanism for carotenoid biosynthesis has been studied in detail for microorganism and higher plants. But there are fewer reports in different groups of algae. In 1997, Hirschberg et al. [53] reported some genes and enzymes involved in the carotenoid biosynthesis pathway in algae and plants. Recently, Wang et al. [52] analyses the transcriptome of 22 red algae and 19 brown algae and then combine it with the data available publicly at different databases. Based on this study, they identified some important genes of the carotenoid biosynthetic pathway in algae. In 2019, Negre et al. [54] sequenced the genome of Saccharina japonica and Cladosiphon okamuranus and have proposed the model for carotenoid biosynthesis pathway in these brown algae using genome-scale metabolic networks (GSMNs). Based on available research data, the whole carotenoid biosynthesis pathway in algae can be di-
Table 1. Different algae studied for the production of different pigments.

\begin{tabular}{|c|c|c|c|}
\hline \multicolumn{2}{|c|}{ S. No. Algae } & \multirow{2}{*}{$\begin{array}{l}\text { Pigment } \\
\text { Astaxanthin }\end{array}$} & \multirow{2}{*}{$\begin{array}{c}\text { Reference } \\
{[31]}\end{array}$} \\
\hline 1 & Haematococcus pluvialis & & \\
\hline 2 & Chlorella vulgaris & Astaxanthin & [32] \\
\hline 3 & Chlorella striolata var. multistriata & Astaxanthin & [33] \\
\hline 4 & Botryococcus braunii & Astaxanthin & [31] \\
\hline 5 & Chlorella zofingiensis & Astaxanthin & {$[34]$} \\
\hline 6 & Dunaliella salina & $\beta$-Carotene & {$[35,36]$} \\
\hline 7 & Dunaliella bardwal & $\beta$-Carotene & {$[37]$} \\
\hline 8 & Coelastrella striolata var. multistriata & $\beta$-Carotene & [33] \\
\hline 9 & Dunaliella salina & Bixin & [37] \\
\hline 10 & Phaeodactylum tricornutum & Fucoxanthin & [38] \\
\hline 11 & Isochrysis aff. galbana & Fucoxanthin & [39] \\
\hline 12 & Odentella aurita & Fucoxanthin & [40] \\
\hline 13 & Cylindrotheca closterium & Fucoxanthin & [38] \\
\hline 14 & $\begin{array}{l}\text { Isochrysis galban and Amphidinium } \\
\text { carterae }\end{array}$ & Peridinin & {$[41,42]$} \\
\hline 15 & Phaeodactylum tricornutum & Zeaxanthin & [43] \\
\hline 16 & Chlorella ellipsoidea & Zeaxanthin & [44] \\
\hline 17 & $\begin{array}{l}\text { Haematococcus pluvialis, Chlorella } \\
\text { zofingiensis }\end{array}$ & Canthaxanthin & $n \quad[45]$ \\
\hline 18 & Chlorella vulgaris & Canthaxanthin & [46] \\
\hline 19 & $\begin{array}{l}\text { Botryococcus braunii and Dunaliella } \\
\text { tetriolecta }\end{array}$ & Violaxanthin & [37] \\
\hline 20 & Chlorella prothecoides & Lutein & [47] \\
\hline 21 & Chlorella pyrenoidosa & Lutein & [48] \\
\hline 22 & Chlorella vulgaris & Lutein & [49] \\
\hline 23 & $\begin{array}{l}\text { Chlorella salina, C. zofingiensis and } D \text {. } \\
\text { salina }\end{array}$ & Lutein & [50] \\
\hline 24 & Muriellopsis sp. & Lutein & [51] \\
\hline
\end{tabular}

vided into the following six steps (Fig. 1).

\subsection{Biosynthesis of $\mathrm{C}_{5}$ isoprene units (IPP/DMAPP)}

Isopentenyl diphosphate (IPP) and dimethylallyl diphosphate (DMAPP) are five-carbon $\left(\mathrm{C}_{5}\right)$ ubiquitous precursor metabolites, required for the biosynthesis of carotenoids. In living systems, two different pathways: (1) MVA (mevalonate) pathway and (2) MEP (methylerythritol phosphate) pathway, participates in biosynthesis of these precursor metabolites [20]. The MVA pathway was discovered in the 1950s and was considered as the sole path for the biosynthesis of IPP in all living organisms [55]. But results of MVA pathway enzyme inhibition and isotopic labeling studies on prokaryotes, algae and higher plants, indicated the absence of some key enzymes of the MVA pathway. However, IPP was well incorporated in different compounds of these organisms under study. These studies pointed out the presence of another route of IPP biosynthesis. This new route of IPP biosynthesis is called a nonmevalonate pathway or 1-deoxy-D-xylulose 5-phosphate (DXP) pathway or methylerythritol phosphate (MEP) pathway [56]. Animals and fungi use the MVA pathway for biosynthesis of IPP while the MEP pathway is identified in plants and algae. In higher plants, both MVA and MEP 


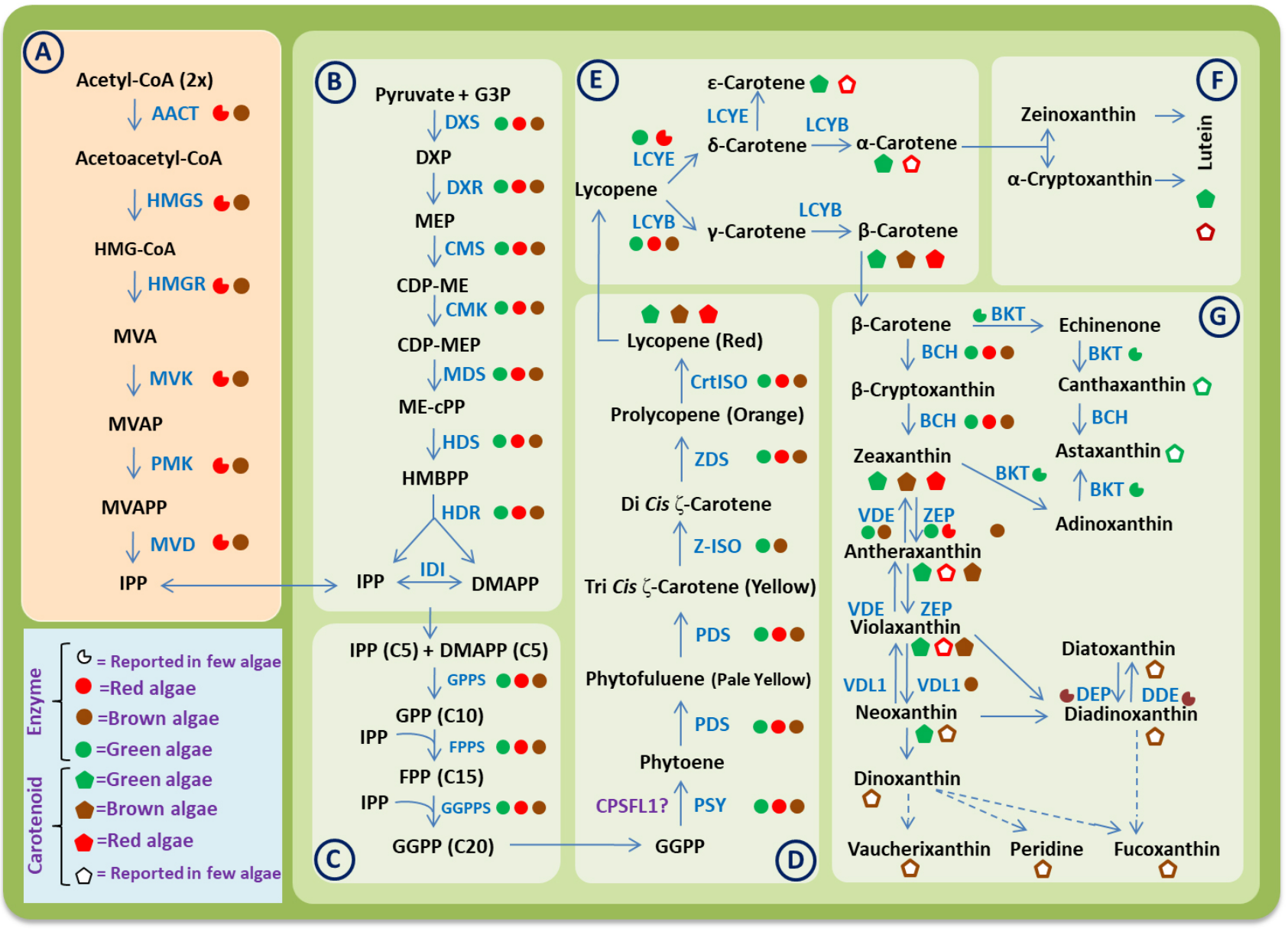

Fig. 1. A consensus carotenoid biosynthesis pathway in algae. Different boxes represent the different steps involved in biosynthesis process as follows: (A) Mevalonate (MVA) pathway. (B) Methylerythritol phosphate (MEP) pathway. (C) Biosynthesis of geranylgeranyl diphosphate (GGPP). (D) Biosynthesis of phytoene and lycopene. (E) Biosynthesis of carotenes. (F) Biosynthesis of xanthophylls derived from $\alpha$-carotene. (G) Biosynthesis of xanthophylls derived from $\beta$-carotene. Symbols of enzymes and carotenoids according to their occurrence in different group of algae are also denoted in the figure.

pathways operates simultaneously. While, in the case of algae, the MVA pathway has been lost in several groups like: Chlorophyceae, Prasinophyceae, Trebouxiophyceae and Cyanidioschyzon merolae (red alga). Therefore, the MEP pathway is the key pathway, which supplies the majority of IPP/DMAPP for carotenoid biosynthesis in these algal groups. In other groups of algae, like Glaucophyta and Heterokontophyta, both MVA and MEP pathways participate in the synthesis of IPP/DMAPP isoprene molecules [57]. In the case of red algae, Lohr et al. [55] reported that both MVA and MEP pathways participate in the biosynthesis of IPP molecules. On the other hand, Deng et al. [58] suggested that bioinformatics analyses are not able to characterize the genes for MVA pathway enzymes in red algae. Based on the existing ESTs, genome data, and phylogeny clustering analysis, Du et al. [59] also reported that green algae and red algae received their plastid by primary endosymbiotic events with cyanobacteria, while brown algae obtained their plastid via secondary endosymbiotic event with red algae.

\subsubsection{Mevalonate (MVA) pathway}

MVA is a specific intermediate of IPP biosynthesis. This classical MVA pathway is a multistep-cytosolic pathway, which begins with the condensations of three acetyl-CoA molecules and comes to an end with the synthesis of one IPP molecule (Fig. 1). In the initial two steps, one molecule of HMG-CoA ( $\beta$-Hydroxy $\beta$-methylglutarylCoA) is formed by the condensation of three acetylCoA molecules. In the subsequent step, this HMG-CoA molecule is reduced to MVA with the consumption of two NADPH molecules. Then MVA molecule was transformed into an IPP molecule via two-time phosphorylation and one ATP coupled decarboxylation reaction [56]. A total of six enzymes AACT, HMGS, HMGR, MVK, PMK and MVD participates in this pathway [55]. An extra enzyme isopentenyl diphosphate isomerase (IDI) is also required for the conversion of IPP to DMAPP. Out of these, HMGR is an ER membrane-anchored protein, while others are soluble protein in nature. Enzyme 3-hydroxy-3-methylglutaryl 
CoA reductase (HMGR) and mevalonate kinase (MVK) are identified as key regulators, catalyses the committed steps: formation and phosphorylation of mevalonate, respectively. Conversion of HMG-CoA to MVA can be inhibited by the use of mevinolin, which is a highly specific inhibitor of the enzyme HMGR [60]. Most of the researchers agreed that, MVA pathway operates in the cytosol. Sapir-Mir et al. [61] have challenged this and according to them, the MVA pathway is compartmentalized to peroxisomes, as several studies indicate the peroxisomal location of enzyme AACT and IDI in plants.

\subsubsection{Methylerythritol phosphate (MEP) pathway}

Biochemical, ESTs and genomic research-based data elucidated that, MEP pathway evolved due to cyanobacterial ancestry in algal cells. That is why, this pathway operates in plastids of algal cells in contrast to the MVA pathway which operates in the cytosol [62]. D-glyceraldehyde-3-phosphate and pyruvate participate as a substrate in this pathway [63]. This pathway consists of eight steps, which start with the conversion of G3P and pyruvate to DXS (1-deoxy-D-xylulose-5phosphate synthase) and end with the formation of IPP and DMAPP. A total of seven different enzymes (DXS, DXR-1-deoxy-D-xylulose-5-phosphate reductoisomerase, MCT-2-C-methyl-D-erythritol 4-phosphate cytidylyl transferase, CMK-4- (cytidine 5'-diphospho)2-C-methyl-D-erythritol kinase, MDS-2-C-methylD-erythritol 2,4- cyclodiphosphate synthase, HDS-4hydroxy-3-methylbut-2-enyl diphosphate synthase, and HDR-4-hydroxy-3-methylbut-2-enyl diphosphate reductase) participate in this pathway. These enzymes are encoded by nuclear genes and guided by $\mathrm{N}$-terminal transit peptide sequences for their transport into plastids [64]. Out of these enzymes, three enzymes: DXS, DXR and HDR catalyze the rate-limiting steps of the pathway. DXS is a thiamin dependent enzyme which catalyzes the first step of this pathway. In this step, 1-deoxy-D-xylulose-5phosphate (DXP) is synthesized by the decarboxylation of pyruvate and subsequent condensation reaction between resultant and glyeraldehyde-3-phosphate [62]. It is a main rate-limiting enzyme, its over expression enhance the rate of carotenoid synthesis [20]. Sun and Li [65] also reported that, protein-protein interaction between DXS and PSY (phytoene synthase) enzyme also regulates the carotenogenesis. The enzyme DXR catalyzes the synthesis of 2-C-methyl-D-erythritol 4-phosphate (MEP) by rearrangement and subsequent reduction of DXP [62]. This step might be considered as the primary committed step of the MEP pathway. The activity of DXR enzyme can be inhibited by fosmidomycin. The decreased activity of DXR affects the activity of downstream enzymes like GGPS (geranylgeranyl phosphate synthase) and ultimately interrupts the biosynthesis of carotenoids in algae. Du et al. [59] cloned the cDNA of DXS and DXR genes from Pyropia haitanensis (red alga). The HDR is another key enzyme, which catalyzes the reductive dehydration reaction in the final step of the MEP pathway. As a result, HMBPP (4-Hydroxy-3-methyl-but-2-enyl pyrophosphate) is converted to $\mathrm{C}_{5}$ isoprene units. Both IPP and DAMPP are synthesized in this step; therefore, there is no need for enzyme IDI, which is required for isomerization of IPP to DMAPP (dimethylallyl diphosphate) in MVA pathway. However, it may require for the balance supply of IPP and DMAPP [56]. Ramos et al. [66] characterized the HDR gene and enzyme from green alga Dunaliella salina and reported that, it shows response to different stress conditions and played important role in regulation of carotenoid biosynthesis.

\subsection{Biosynthesis of geranylgeranyl diphosphate (GGPP)}

Geranylgeranyl diphosphate (GGPP) is an immediate metabolic predecessor of the carotenoid biosynthesis pathway. Formation of GGPS (geranylgeranyl phosphate synthase) is a three-step process. In the initial step, 10-carbon compound sesquiterpene is synthesized by the addition of one IPP and one DMAPP molecule. In subsequent steps, FPP is synthesized by the addition of one IPP molecule to sesquiterpene and then GGPP is formed by the addition of one more IPP molecule to FPP (farnesyl pyrophosphate) [67, 68]. This process involves three different types of enzymes: GPPS-geranyl diphosphate synthase, FPPS - farnesyl diphosphate synthase, and GGPPS - geranylgeranyl diphosphate synthase, sequentially [65]. Ruiz-Sola et al. [69] reported 12 paralogues genes for GGPPS in Arabidopsis. They also suggested that, out of different GGPPS isozymes, GGPPS11 isozyme behave like a hub isozyme and it interacts with other proteins required for the biosynthesis of carotenoids. These enzymes are rarely studied in algae in comparison to higher plants. Yang et al. [70] cloned and characterized the GGPP synthase gene (PuGGPS) in a red alga Pyropia umbilicalis (Bangiales). They reported that a polypeptide sequence of 345 amino acids with transit peptide sequence (N-terminal) is encoded by this gene. Lao et al. [67] reported that, GGPPS of an alga Haematococcus pluvialis (HpGGPPS) have tri-functional catalytic activities, which catalyzes all three steps of GGPP biosynthesis. Deng et al. [58] cloned and characterize the bfGGPPS from the red alga Bangia fuscopurpurea. They also report that GGPP is the only product of this enzyme and it also interacts with psy gene, which is the rate-limiting enzyme of the carotenoid biosynthesis pathway. Deng et al. [58] also performed the phylogeny analysis and suggest that the red algal and diatoms share a common ancestor for GGPPS but green algae and higher plants show an early divergence of GGPPS during evolution. It has been reported that, the supply of GGPP and its precursors decides the rate and subsequent flux of carotenoid biosynthesis in algae [68]. 


\subsection{Biosynthesis of phytoene}

Biosynthesis of phytoene is the first entry step reaction towards the carotenoid biosynthesis. It is the first colorless carotenoid (40-carbon) compound, which is synthesized by condensation of two GGPP molecules. This reaction is catalyzed by enzyme phytoene synthase (PSY) $[65,71]$. PSY is one of the important rate-limiting and key flux controlling enzyme, which decides the pool size of carotenoids. Some studies indicate that several isoforms of PSY exist in different plant species and these are regulated by alternative splicing and protein modifications under the influence of different abiotic and biotic signals [20]. Recently, various genomic and phylogenetic studies are conducted using genomic sequences of some algae belonging to different groups like red algae, green algae, brown algae and diatoms to identify the PSY genes [52]. Tran et al. [72] reported the two orthologous copies of the PSY gene in green algae Micromonas and Ostreococcus. These studies indicate the gene duplication events of the PSY gene during ancient evolution, which produces the two classes of PSY gene in algae. But presently, these two classes, PSY I and PSY II are only retained in members of Prasinophyceae (Chlorophyta). Green algae (other than Prasinophyceae) and higher plants have lost PSY II and reported to have only the PSY I class. In contrast to this, the members of algae belong to Rhodophyta, Heterokontophyta and Haptophyta have only the class PSY II gene [52]. Due to the major flux controlling enzyme of the carotenoid biosynthesis pathway, PSY has been recognized as a major target for metabolic engineering [73]. Recently a novel protein CPSFL1 has been identified, which is bound with phytoene and modulates the accumulation of carotenoids in the chloroplast [74].

\subsection{Biosynthesis of lycopene}

Biosynthesis of lycopene is a multistep process in which phytoene is converted to lycopene via sequential desaturation and isomerization reactions. This whole process includes four conserved enzymes: PDS, Z-ISO, ZDS and CrtISO [75]. Phytoene, which is synthesized in the previous step, is desaturated to $\zeta$-carotene. This occurs in two steps and both steps are catalyzes by an enzyme PDS. In the first step, phytoene is converted to 9,15-di-cis-phytofluene, and then in the next step, this phytofluene is converted to 9,15,9tri-cis- $\zeta$-carotene. This 9,15,9-tri-cis- $\zeta$-carotene is yellow in color. The 9,15,9-tri-cis- $\zeta$-carotene is then converted to lycopene via multiple steps. In the first step, 9,15,9-tri-cis$\zeta$-carotene is converted to 9,9-di-cis- $\zeta$-carotene and then to prolycopene. These two reactions are catalyzes by the enzyme Z-ISO and ZSO, respectively. This prolycopene, which is orange in color, is converted to red colored compound lycopene. This conversion is catalyzed by the enzyme CrtISO [20, 76]. Wang et al. [52] have identified and characterized the gene of these enzymes in different groups of algae-like Chlorophyta, Phaeophyta, and Rhodophyta. Various studies reported that, out of these four genes; the gene for PDS, ZDS and CRTISO are present in all three groups of algae, while gene for Z-ISO is absent in red algae (Rhodophyta). Wang et al. [52] also suggested that the absence of this gene in red algae does not affect the carotenoid biosynthesis.

\subsection{Biosynthesis of carotenes}

Lycopene is the first link of carotenogenesis, which allows the biosynthesis of both $\alpha$-carotene and $\beta$ carotene in algae. It is a most important branching point, where the ratio of $\alpha$-carotenoids (lutein) to $\beta$-carotenoids ( $\beta$-carotene) is to be decided. In $\alpha$-carotene, one $\epsilon$-ring and one $\beta$-ring are present at the extremity of lycopene. While, in $\beta$-carotene, two $\beta$-rings are present at the extremity of lycopene. Carotene with two $\epsilon$-ionone rings rarely occurs in nature. This branch point reaction is catalyzed by two different enzymes; lycopene $\epsilon$-cyclase (LCYE) and lycopene $\beta$-cyclase (LCYB) [77]. Formation of $\alpha$-carotene from lycopene occurs in two sequential steps: in the first step, enzyme LCYE catalyzes the cyclization at the one open end and form $\delta$-carotene; in the next step, LCYB catalyzes the $\beta$-ionone ring formation at another end and ultimately $\alpha$ carotene is synthesized. In further sequential steps this $\alpha$ carotene is converted to lutein. Similarly, $\beta$-carotene is also synthesized in two sequential steps, but here, both steps are catalyzes by the same enzyme LCYB. In the first step lycopene converted to $\gamma$-carotene and in the next step this $\gamma$ carotene is converted to $\beta$-carotene [58].

Based on chemical, GSMN and proteomic studies, it has been elucidated that algae are different in their lycopene cyclase enzyme compositions. Some algae contain both LCYE and LCYB, while other algae have only one class of LCY. Cui et al. reported that in green alga (except for C. reinhardtii (LCYE), and Chlorella sp. NC64A (LCYE), H. pluvialis (LCYB), D. salina (LCYB),) two distinct LCY (beta- and epsilon-type) enzymes are present, on the other hand, heterokontophyta have only lycopene beta-cyclase (LCYB) [77]. Recently, Inoue et al. [78] also reported the LCYB activity in brown alga Undaria pinnatifda. Macrophytic red algae have both LCYB and LCYE enzymes while microphytic algae have only the enzyme LCYB [52]. Some other studies also suggested that, synthesis of $\delta$-carotene, $\alpha$-carotene and lutein are absent in some groups of algae-like Bacillariophyceae, Chrysophyceae, Phaeophyceae, Xanthophyceae, and some red algae, while the $\beta$-carotene occurs in majority groups of algae and other photosynthetic organisms $[18,58]$. Liang et al. [79] reported that the amino acid sequences of LCYB and LCYE are significantly similar. This report indicates that the gene duplication events in a common ancestor may be the possible reason behind the presence of two classes of LCY enzymes in algae. Deng et al. [58] suggested that LCYE, in green and red algae, evolved separately. Both enzyme LCYB and LCYE plays a major role in the metabolic flux of carotenes. Sathasivam and Ki [80] reported that 
treatment of redox-active heavy metals enhances the expression level of enzymes PSY, PDS, and LCYB and ultimately enhance the accumulation of lutein and $\beta$-carotene in brown alga Tetraselmis suecia.

\subsection{Biosynthesis of xanthophylls}

In algae, different types of xanthophylls like: lutein, cryptoxanthin, zeaxanthin, antheraxanthin, violaxanthin, neoxanthin, fucoxanthin, diadinoxanthin, diatoxanthin, canthaxanthin, astaxanthin etc., are synthesized. Types and nature of xanthophyll molecules differ in various algal groups. Both $\alpha$ - and $\beta$-carotene serves as precursor molecules for the biosynthesis of these xanthophyll compounds.

Lutein is a derivative of $\alpha$-carotene. It is synthesized in two successive steps: firstly $\alpha$-carotene is converted to zeinoxanthin or $\alpha$-cryptoxanthin and then in second step zeinoxanthin is converted to lutein. Both of these steps are catalyzed by P450-type enzymes $\epsilon$-hydroxylase and $\beta$-hydroxylase. Yang et al. [81] reported that red algal enzyme CYP97B29 has both $\epsilon$ - and $\beta$-ring hydroxylase activity. Liang et al. [82] functionally identify the genes of carotene hydroxylases from alga Dunaliella bardawil. Various studies reported that, biosynthesis of lutein mainly occurs in green algae and some of the red algae. While other group of algae-like Bacillariophyceae, Chrysophyceae, Phaeophyceae and Xanthophyceae cannot synthesize lutein and other derivatives of $\alpha$-carotene.

Zeaxanthin is a double hydroxylation derivative of $\beta$-carotene. $\beta$-carotene is converted to $\beta$-cryptoxanthin and then $\beta$-cryptoxanthin is converted to zeaxanthin. Both of these hydroxylation reactions are catalyzed by the enzyme $\beta$-carotene hydroxylase (BCH). Biosynthesis of zeaxanthin occurs in all groups of algae as well as higher plants. Further, zeaxanthin is converted to violaxanthin in a two-step process. In the first step, zeaxanthin is converted to antheraxanthin and in the next step, antheraxanthin is converted to violaxanthin. Both of these steps are catalyzed by the enzyme ZEP. Enzyme ZEP catalyzes the epoxidation reaction of $\beta$-rings of zeaxanthin molecule [83]. Another enzyme VDE has also been reported which led to the formation of $\beta$-rings and ultimately reverses these reactions. This whole process of violaxanthin biosynthesis is also known as xanthophyll cycle-I. This cycle occurs in all members of green and brown algae while in the case of red algae it occurs partially [84].

In the case of brown algae some commercially important carotenoids like fucoxanthin and diadinoxanthin are also synthesized. Scientists have proposed two different pathways for the biosynthesis of these carotenoid compounds. According to the first pathway, violaxanthin is converted to neoxanthin and then neoxanthin is used as a precursor molecule for the biosynthesis of both fucoxanthin. An enzyme neoxanthin synthase (NXS) catalyzes the conversion of violaxanthin to neoxanthin in higher plants.
In the case of algae, recently, Dautermann et al. [85] reported a new enzyme violaxanthin de-epoxide-like (VDL), which is responsible for the conversion of violaxanthin to neoxanthin. They also reported that VDL is also involved in the synthesis of peridinin and vaucheriaxanthin. According to the second pathway, violaxanthin is used as a precursor for the biosynthesis of diadinoxanthin and then, the diadinoxanthin is converted into the fucoxanthin. The enzymes involved in this process are also still unknown. In some alga, diadinoxanthin can also be converted to diatoxanthin. This reaction is catalyzed by an enzyme deepoxidase (DDE). This conversion of diadinoxanthin to diatoxanthin can be reversed by an enzyme diatoxanthin epoxide (DEP) under low light intensity. This pathway is called xanthophyll cycle-II. This cycle mainly occurs in members of Chrysophyceae, Bacillariophyceae, Phaeophyceae, and Xanthophyceae [54].

Astaxanthin, is another important carotenoid compound, which has strong antioxidant activity as compared to vitamin $\mathrm{C}$ and $\mathrm{E}$, is synthesized by several bacteria, fungi, algae and higher plants. In algae several species have been reported which are involved in de novo synthesis of astaxanthin. The scientist has identified the two biochemical pathways for the biosynthesis of astaxanthin. According to the first pathway, $\beta$-carotene is converted to canthaxanthin and then, canthaxanthin is converted to astaxanthin. These two reactions are catalyzes by enzyme $\mathrm{BKT}$ and $\mathrm{BCH}$, respectively. According to another pathway, zeaxanthin is converted to adonixanthin and then adonixanthin is converted to astaxanthin. In this second pathway, both of the reactions are catalyzed by the same enzyme BKT. Mao et al. [75] reported that, under sulfur stress conditions, genes $L C Y E$ and $Z E P$ are down-regulated while gene $L C Y B, B C H$ and $B K T$ are up-regulated. This regulation of gene expression enhances the accumulation of astaxanthin in green alga Chromochloris zofingiensis. Among the algae, Haematococcus pluvialis considered as the richest source of natural astaxanthin. Astaxanthin in algae is present in esterified form in contrast to non-esterified form in yeast and synthetic form.

\section{Chemistry of different carotenoid}

Carotenoids are naturally occurring chemically diverse pigments covering yellow, orange, red, or dark green color, which are biosynthesized by diverse plants, fungi, algae, and microorganisms [86]. Carotenoids possess various biological functions, including light-catching, antioxidant activity, photoprotection from harmful ionizing radiation and medicinal properties and they are used as preventives against diseases such as cancer, diabetes, and cataract. Carotenoids are also used in food supplements, cosmetics, and pharmaceuticals. These compounds are largely isoprenoid chromophore-bearing polyene pigments having 313 conjugate double bonds containing two terminal rings. The presence of $\pi$-electron conjugation in the structure of 
carotenoids (Fig. 2) is responsible for the unique spectroscopic properties of carotenoids. The polyene conjugation pattern is repeated in all carotenoids. The color of carotenoids can be determined by the presence of a number of conjugated double bonds in their skeleton. Carotenoids with a higher number of conjugated double bonds (such as lycopene and astaxanthin) generally show red color and are good antioxidants [87].

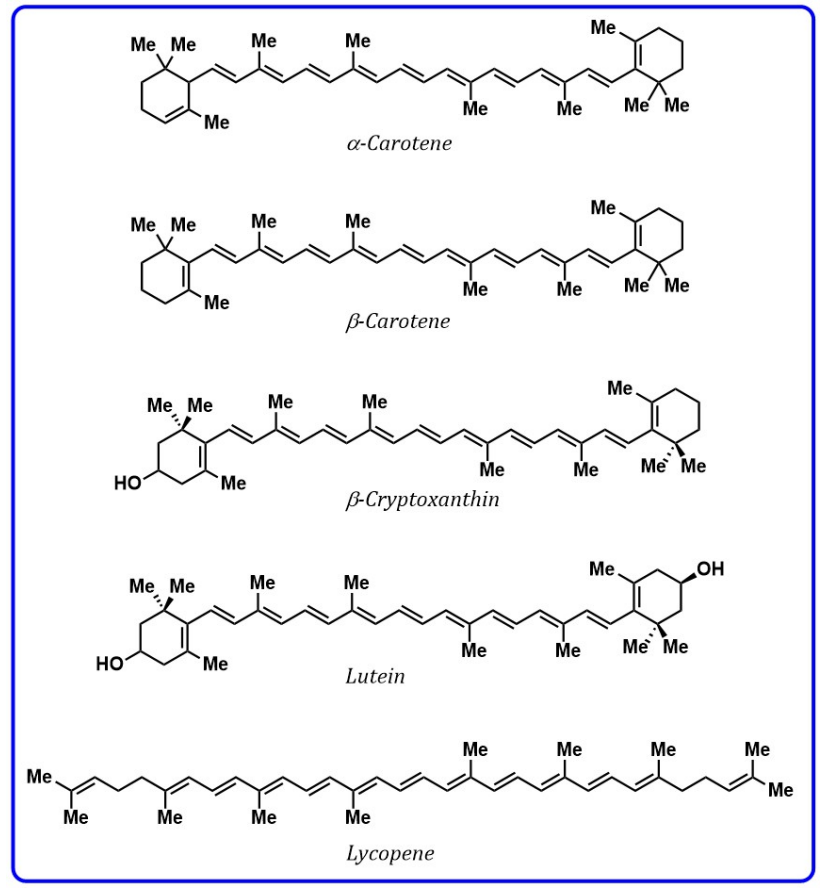

Fig. 2. Structures of carotenoids containing polyenes.

The unique spectroscopic property is mainly due to a strong symmetry allowed the electronic transition from the electronic ground state, $S_{0}$ to the lowest photoactive singlet excited state, $S_{2}$ which is relaxed by internal conversion (IC) [88]. The transition from the ground state, $\mathrm{S}_{0}$ to the lowest-lying excited state, $S_{1}$ is optically forbidden due to a lack of change in symmetry [89]. The $S_{0}-S_{2}$ transition generally shows characteristic three-peak absorption spectra attributed to the transition to the three vibrational levels $(0,1,2)$ of the $S_{2}$ state as depicted in Fig. 3.

Many studies have demonstrated that the energy of the $\mathrm{S}_{0}-\mathrm{S}_{2}$ transition decreases with the extended conjugation [90]. A few recent studies on analogues of the same carotenoid having different conjugation lengths rationalized the dependence of energy of the $S_{2}$ state on conjugation length [91].

Although conjugation length governs most of the spectroscopic properties of carotenoids, but it was reported that the presence of specific functional groups, such as conjugated aryl ring, carbonyl group, can significantly affect the energy of excited states. Aryl ring exhibiting carotenoids such as chlorobactene, $\beta$-isorenieratene, isore-

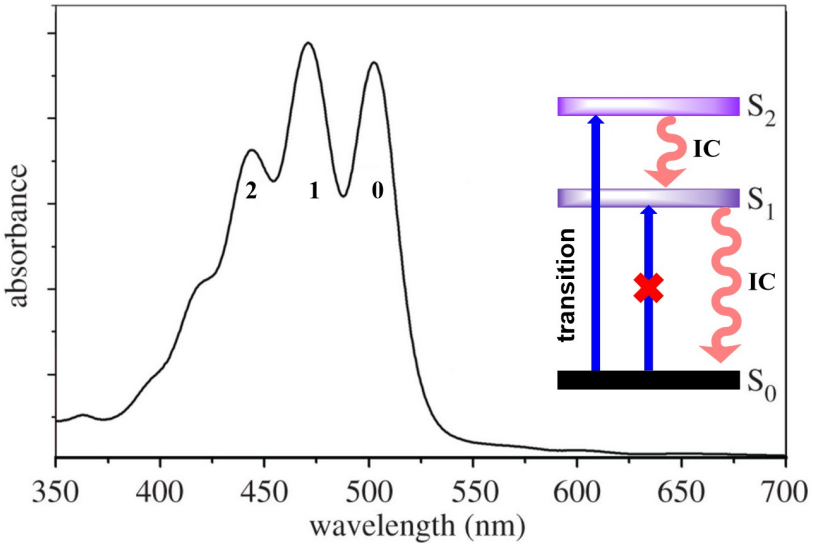

Fig. 3. Typical absorption spectrum of lycopene showing absorption spectrum, transitions in singlet state and relaxation of excited state by IC.

nieratene and okenone shown in Fig. 4, are pigments responsible for light-harvesting and photoprotective agents in green sulfur bacteria [92]. It was also reported that certain cyanobacteria are also capable of synthesizing aryl carotenoids such as synechoxanthin, which has been identified in Synechococcus sp. PCC 7002 [93].

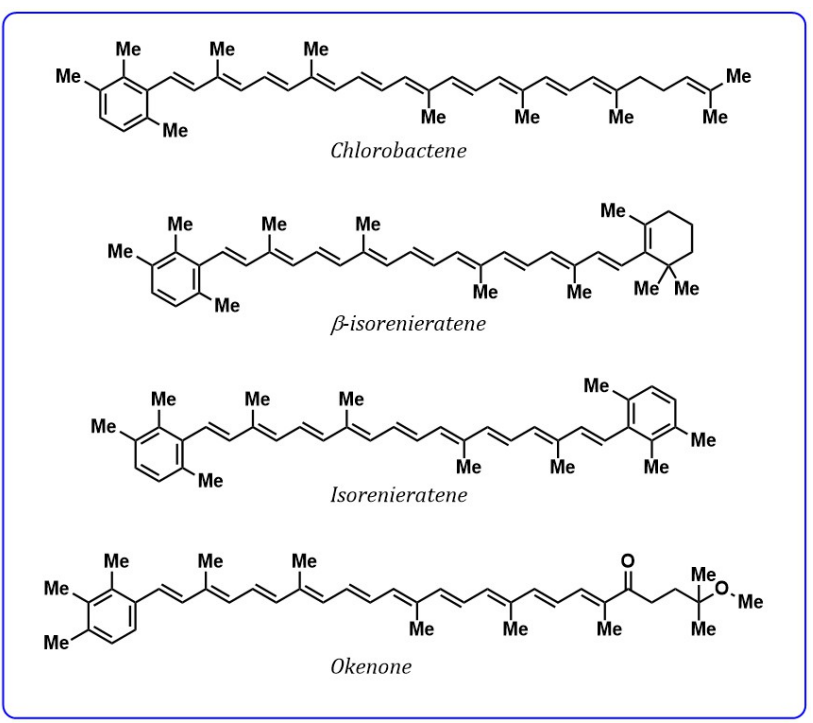

Fig. 4. Structures of carotenoids containing aryl ring.

Moreover, carotenoids with a conjugated carbonyl group are widely available pigments in plants and microorganisms and these carotenoids are most abundant in nature. Astaxanthin peridinin, fucoxanthin, and siphonaxanthin (Fig. 5) are carotenoids contain conjugated carbonyl groups found in algae and bacteria. These carotenoids are most studied as light-harvesting agents and excitation energy transfer agents to chlorophylls. 


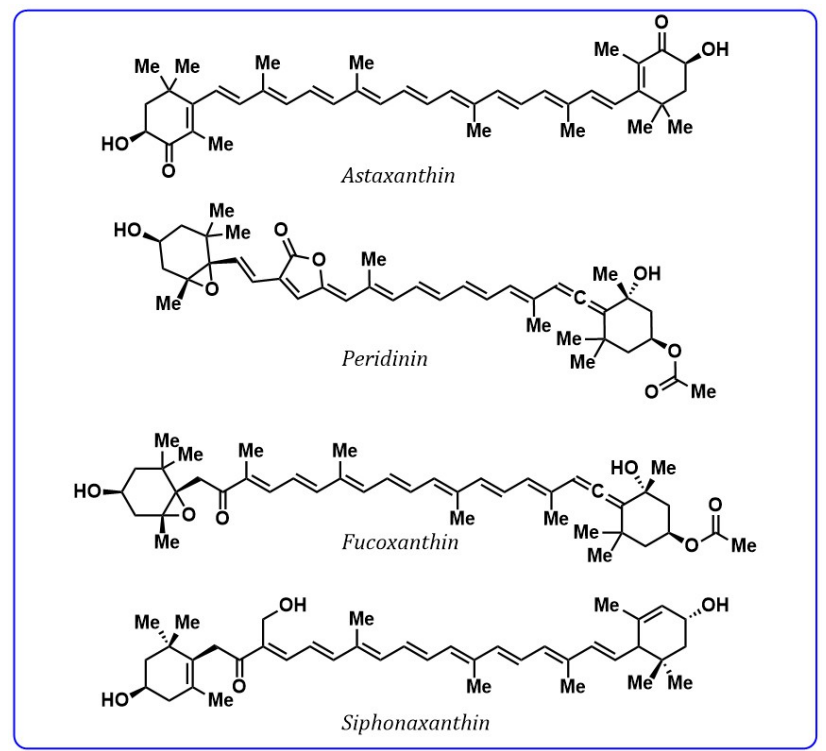

Fig. 5. Structures of carotenoids containing conjugated carbonyl group.

Carotenoids play a vital role in food industries as they offer natural color and flavours to various foods. Carotenoid-derived aroma compounds have been detected in leaf (tobacco, tea, and mate), essential oils, fruits (grapes, passionfruit, starfruit, quince, apple, nectarine), vegetables (tomato, melon), spices (saffron, red pepper), as well as coffee, oak wood, honey, seaweeds, etc. [94]. Degradation of carotenoids leads to different volatile flavor compounds [95]. Carotenoids produce a broad spectrum of aroma compounds (called apocarotenoids) in plants by oxidative cleavage, giving rise to volatile compounds responsible for the aroma of flowers, fruits, and leaves, as well as the well-known phytohormones such as abscisic acid and strigolactones [96]. The important volatile fragments of carotenoids with a 9-13 carbon skeleton frequently detected in nature. The important carotenoids-derived aroma compounds are: $\beta$-ionone, $\beta$ damascenone, megastigmanes comprising C-13 skeleton; $\beta$-homocyclocitral and dihydroactinidiolide containing C-11 skeleton; $\beta$-cyclocitral, $\alpha$-cyclocitral, and safranal containing C-10 skeleton; 2,2,6-trimethylcyclohexanone, 2,2,6-trimethylcyclohexane1,4-dione comprising C-9 skeleton as depicted in Fig. 6.

\section{Extraction of high value carotenoids}

\subsection{Conventional extraction methods}

Carotenoids are extracted from microalgae utilizing conventional solvent extraction methods using organic solvents. Conventional extraction using organic or aqueous solvents depends on the polarity, solubility, and chemical stability of carotenoids to be extracted. Therefore, the selection of a suitable solvent system is necessary which

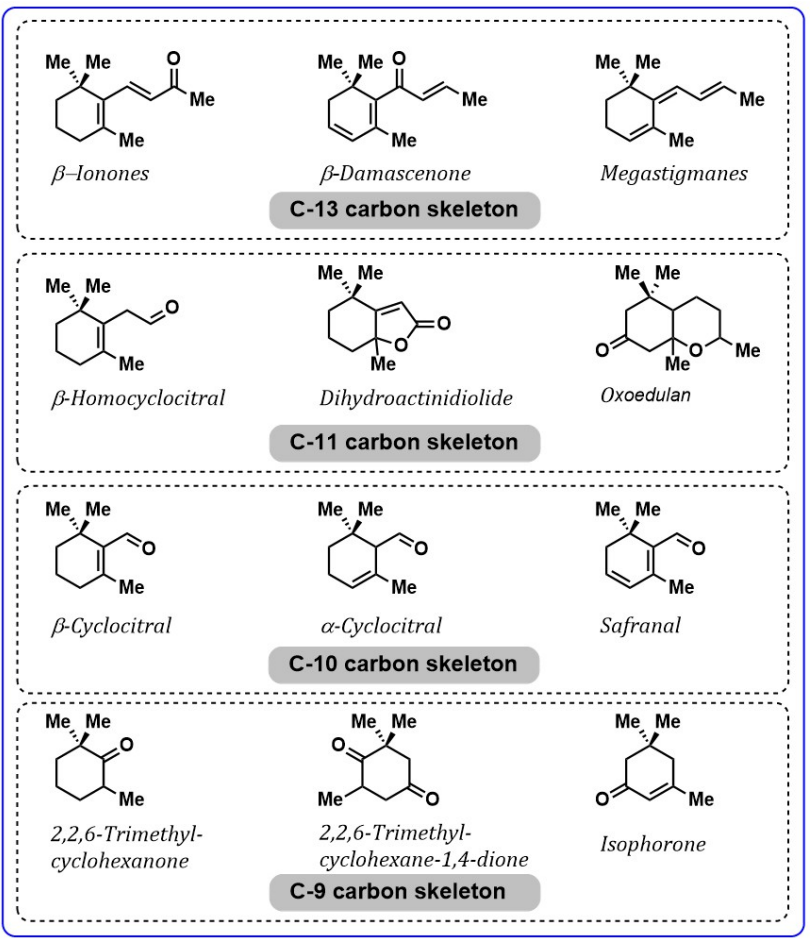

Fig. 6. Important aroma compounds related to carotenoid's degradation.

can selectively and efficiently extract carotenoids with high purity. Non-polar solvents (n-hexane, dichloromethane, dimethyl ether, diethyl ether) and polar solvents (acetone, methanol, ethanol, biphasic mixtures of several organic solvents) can be used based on the polarity of the target carotenoid. The use of green solvents (environmentally safe and non-toxic solvents) such as ethanol, limonene, and biphasic mixtures of water and organic solvents has been investigated for the recovery of carotenoids from microalgae. However, the commercial reality of carotenoid extraction from microalgal species is still challenging due to the high cost of production, and usage of enormous amounts of solvents. The uses of non-conventional extraction methods are therefore gaining interest in recent years. These nonconventional extraction methods have several advantages including rapid extraction, low solvent consumption, better recovery, and higher selectivity. These different extraction approaches for various carotenoids along with their relative yield are mentioned in Table 2 (Ref. [97-112]).

\subsection{Microwave-assisted extraction (MAE)}

Microalgal cells are difficult to disrupt due to algaenan and sporopollenin within their cell wall [113]. Further, conventional techniques used for cell disruption and extraction methods have low efficiencies. MAE is an efficient method that takes advantage of microwave irradiation to accelerate the extraction of a diversity of compounds from natural matrices. MAE generates high-frequency waves (ranging from $300 \mathrm{MHz}$ to $300 \mathrm{GHz}$ ) with wave- 
lengths of $1 \mathrm{~mm}$ to $1 \mathrm{~m}$. Microwave radiation when applied at a frequency near $2.45 \mathrm{GHz}$ causes vibration of polar molecules resulting in inter and intra-molecular friction. The friction, together with the movement and collision of a large number of charged ions, results in the rapid heating (within few seconds) of the matrix. Intracellular heating leads to the breakdown of cell walls and membranes and therefore there is a faster transfer of the compounds from the cells into the extracting solvent. There are two major types of microwaves; closed and open vessels. In open vessels microwave application is performed at atmospheric pressure while in closed vessels, samples are irradiated by microwave under controlled pressure and temperature. The extraction temperature depends on the polarity of the solvent. Solvents with higher dielectric constant $\left(\varepsilon^{\prime}\right)$ absorb greater energy and thus achieve faster extraction and therefore polar solvents are better extractants than non-polar solvents. Pasqueta et al. [110] investigated the performance of microwave irradiation compared to conventional processes to extract pigments from two marine microalgae Dunaliella tertiolecta (Chlorophyta) and Cylindrotheca closterium (Bacillariophyta). All processes performed on $D$. tertiolecta led to rapid pigment extraction. Though the presence of frustule in the diatom $C$. closterium acted as a mechanical barrier to pigment extraction. MAE was found to be the best extraction process for C. closterium pigments with advantages like rapidity, reproducibility, homogeneous heating and high extraction yields. Fabrowska et al. [114] examined the efficiency of microwave-assisted extraction (MAE), ultrasound-assisted extraction (UAE), supercritical fluid extraction (SFE) and conventional soxhlet extraction in three freshwater green algae species: Cladophora glomerata, Cladophora rivularis, and Ulva flexuosa. MAE and UAE were proved to be costeffective techniques with higher yield compared to traditional solvent extraction techniques. Microwave-assisted extraction (MAE) has been applied for the extraction of astaxanthin from Haematococcus pluvialis which has the highest astaxanthin content [115]. For optimal extraction of astaxanthin, parameters like microwave power (W), extraction time (s), solvent volume (mL), and the number of extractions, were optimized using response surface methodology. The study suggested that optimized conditions of MAE viz. microwave power $141 \mathrm{~W}$, extraction time $83 \mathrm{sec}$, solvent volume $9.8 \mathrm{~mL}$, the number of extraction four times led to the extraction of about $594 \pm 3.02 \mu$ g astaxanthin per $100 \mathrm{mg}$ of dried powder.

\subsection{Ultrasound-assisted extraction (UAE)}

Ultrasonic assisted extraction is based on ultrasonic cavitation. Ultrasonic extraction has been used to extract bioactive compounds like vitamins, polyphenols, pigments and other phytochemicals. UAE is cost-effective and significantly reduces the extraction time, whilst resulting in increased extraction yields. The ultrasound can be divided into two distinct categories: low intensity-high frequency $(100 \mathrm{kHz}-1 \mathrm{MHz})$ and high intensity-low frequency $(20-100 \mathrm{kHz})$. Ultrasonic extraction is achieved with high intensity and low-frequency ultrasound waves. Ultrasound waves when traveling through liquid creates alternating high-pressure and low-pressure cycles resulting in the production of cavitation bubbles in the solvent. Cavitation bubbles form in the liquid during the expansion phase. The ability to cause cavitation depends on the frequency of the ultrasound wave, the solvent properties, and the extraction conditions. During the compression cycle cavitation bubble implodes on the surface of the matrix (cell, tissue or any particle) and a high-speed micro-jet is created leading to the generation of effects like surface peeling, particle breakdown, sonoporation and cell disruption. Sonoporation (perforation in cell walls and membranes) exerts a mechanical effect, allowing greater penetration of solvent into the sample matrix. This leads to increased extraction efficiency in less time. Using ultrasound-assisted extraction, $4.66 \mathrm{mg} \beta$-carotene per $\mathrm{g}$ of dry weight has been obtained from microalgae Spirulina platensis [116]. Various parameters (amplitude, duty cycle, sonication time, and depth of horn immersed into the solution) were optimized for intensified extraction. The optimized condition for the maximum extraction of $\beta$-carotene from this alga was $80 \%$ amplitude, $33 \%$ duty cycle, $0.5 \mathrm{~cm}$ depth of horn immersed in the solution, and 10 min ultrasonication time. UAE has also been applied for the extraction of lutein, $\beta$-carotene, and $\alpha$ carotene from Chlorella vulgaris [117]. The maximum extraction achieved were $4.844 \pm 0.780,0.258 \pm 0.020$, and $0.275 \pm 0.040 \mathrm{mg} / \mathrm{g}$ of dry weight biomass, respectively.

\subsection{Electrotechnologies-assisted extraction}

Electrotechnologies, such as pulsed electric field (PEP), moderate electric field (MEF), high-voltage electric discharges (HVED) are emerging, non-thermal, and green extraction techniques for targeting intracellular compounds from bio-suspensions. In the pulsed electric field (PEP), the sample matrix is exposed to repetitive electric frequencies $(\mathrm{Hz}-\mathrm{kHz})$ with an intense $(0.1-80 \mathrm{kV} / \mathrm{cm})$ electric field for very short periods (from several nanoseconds to several milliseconds). In the moderate electric field (MEF), the sample matrix is exposed to low electric fields (between 1 and $1000 \mathrm{~V} / \mathrm{cm}$ ) with electric frequencies in the range of $\mathrm{Hz}$ up to tens of $\mathrm{kHz}$. While high-voltage electric discharges (HVED) typically have $40-60 \mathrm{kV} / \mathrm{cm}$ for 2-5 $\mu$ s electrical property. All of these electrotechnologies have their mechanism of delivering electrical current through the processed biomaterial, they all promote electroporation or electro-permeabilization allowing the extraction of analytes. The selective extraction of intracellular compounds can be achieved by controlling the pore formation, which is dependent on various factors such as the intensity of the applied electric field, pulse duration, treatment time, and the cell characteristics (i.e., size, shape, orientation in 


\begin{tabular}{|c|c|c|c|c|}
\hline Microalga & Pigment & Technical approach & Carotenoid yield & Reference \\
\hline $\begin{array}{l}\text { Haematococcus } \\
\text { pluvialis }\end{array}$ & Astaxanthin & Integrated ultrasound-assisted liquid biphasic flotation & $\begin{array}{l}\text { Maximum recovery yield, extraction efficiency, and partition coefficient of astaxanthin } \\
\text { were } 95.08 \pm 3.02 \%, 99.74 \pm 0.05 \% \text {, and } 185.09 \pm 4.78 \text {, respectively }\end{array}$ & [97] \\
\hline $\begin{array}{l}\text { Haematococcus } \\
\text { pluvialis }\end{array}$ & Astaxanthin & $\begin{array}{l}\text { Biocompatible protic ionic liquids-based microwave-assisted } \\
\text { liquid-solid extraction }\end{array}$ & high purity (97.2\%) of free astaxanthin was achieved & [98] \\
\hline $\begin{array}{l}\text { Haematococcus } \\
\text { pluvialis }\end{array}$ & Astaxanthin & cell permeabilizing ionic liquids & More than $70 \%$ & [99] \\
\hline $\begin{array}{l}\text { Haematococcus } \\
\text { pluvialis }\end{array}$ & $\begin{array}{l}\text { Astaxanthin, lutein, } \beta \text {-carotene and } s \\
\text { canthaxanthin }\end{array}$ & Supercritical carbon dioxide extraction & $\begin{array}{l}92 \% \text { recovery of carotenoids was obtained at the pressure of } 300 \text { bar and the temperature } \\
\text { of } 60^{\circ} \mathrm{C} \text {, using ethanol as a co-solvent }\end{array}$ & [100] \\
\hline $\begin{array}{l}\text { Haematococcus } \\
\text { pluvialis }\end{array}$ & Astaxanthin and lutein & Supercritical carbon dioxide extraction & $\begin{array}{l}98.6 \% \text { and } 52.3 \% \text { recovery of astaxanthin and leutin respectively, was achieved at } 50{ }^{\circ} \mathrm{C} \\
\text { and } 550 \text { bars }\end{array}$ & [101] \\
\hline $\begin{array}{l}\text { Haematococcus } \\
\text { pluvialis }\end{array}$ & Astaxanthin and lutein & Supercritical carbon dioxide extraction & $\begin{array}{l}\text { highest astaxanthin and lutein recoveries were found at } 65^{\circ} \mathrm{C} \text { and } 550 \text { bar, with } 18.5 \mathrm{mg} / \mathrm{g} \\
\text { dry weight (92\%) astaxanthin and } 7.15 \mathrm{mg} / \mathrm{g} \text { dry weight (93\%) lutein }\end{array}$ & [102] \\
\hline $\begin{array}{l}\text { Haematococcus } \\
\text { pluvialis }\end{array}$ & Astaxanthin & Pressurized extraction solvent & extraction yield of $20.7 \mathrm{mg} / \mathrm{g}$ dry weight & [103] \\
\hline $\begin{array}{l}\text { Chlorella vul- } \\
\text { garis }\end{array}$ & Leutin & Pulse electric field & $\begin{array}{l}\text { the concentration of lutein was around } 4.5 \text {-fold higher when the fresh biomass was previ- } \\
\text { ously electroporated at } 40^{\circ} \mathrm{C} \text { by a PEF of } 25 \mathrm{kV} / \mathrm{cm} \text { for } 75 \mu \mathrm{s}\end{array}$ & [104] \\
\hline $\begin{array}{l}\text { Chlorella } \\
\text { sorokiniana }\end{array}$ & Leutin & $\begin{array}{l}\text { Pre-treated by bead-beating and high-pressure cell disruption } \\
\text { methods, followed by harvesting with reduced pressure ex- }\end{array}$ & $\begin{array}{l}\text { Extraction with tetrahydrofuran as solvent resulted in high lutein recovery efficiencies of } \\
99.5 \% \text { ( } 40 \mathrm{~min} \text { ) at } 850 \mathrm{mbar} \text { and } 25^{\circ} \mathrm{C} \text {. In contrast, using ethanol as the solvent, } 86.2 \%\end{array}$ & [105] \\
\hline MB-1 & & traction method & lutein recovery was achieved under $450 \mathrm{mbar}, 35^{\circ} \mathrm{C}$ and 40 min extraction & \\
\hline $\begin{array}{l}\text { Tetradesmus } \\
\text { obliquus }\end{array}$ & $\begin{array}{l}\alpha \text {-tocopherol, canthaxantin, } \gamma^{-} \varsigma \\
\text { tocopherol, lutein, phylloqui- } \\
\text { none, phytofluene, retinol, and } \\
\text { menaquinone-7 }\end{array}$ & supercritical fluid extraction (SFE) & $\begin{array}{l}\text { The highest extraction of alpha-tocopherol, gamma-tocopherol, and retinol was achieved } \\
\text { at a pressure of } 30 \mathrm{MPa} \text { and a temperature of } 40^{\circ} \mathrm{C}\end{array}$ & [106] \\
\hline $\begin{array}{l}\text { Chlorella zofin- } \\
\text { giensis }\end{array}$ & Cantaxanthin & High-speed counter-current chromatography (HSCCC) & $\begin{array}{l}\text { The recovery of canthaxanthin was } 92.3 \% \text {. Canthaxanthin at } 98.7 \% \text { purity from } 150 \mathrm{mg} \\
\text { of the crude extract }\end{array}$ & [107] \\
\hline $\begin{array}{l}\text { Phaeodactylum } \\
\text { tricornutum }\end{array}$ & Fucoxanthin & $\begin{array}{l}\text { maceration, ultrasound-assisted extraction, soxhlet extrac- } \\
\text { tion, and pressurized liquid extraction }\end{array}$ & $\begin{array}{l}\text { ethanol provided the best fucoxanthin extraction yield }(15.71 \mathrm{mg} / \mathrm{g} \text { freeze-dried sample } \\
\text { weight). Fucoxanthin content in the extracts produced by the different methods was some- } \\
\text { what constant (15.42-16.51 } \mathrm{mg} / \mathrm{g} \text { freeze-dried sample weight) }\end{array}$ & [108] \\
\hline $\begin{array}{l}\text { Phaeodactylum } \\
\text { tricornutum }\end{array}$ & Fucoxanthin & microwave-assisted treatment & $\begin{array}{l}\text { ethanol was preferable for the extraction of fucoxanthin than other solvents in terms of } \\
\text { the fucoxanthin yield (ethanol/methanol, } 48.01 \pm 0.35 \% \text {; ethanol/acetic acid, } 53 \pm 0.46 \% \text { ) } \\
\text { under the continuous microwave-assisted treatment time of } 1 \text { min }\end{array}$ & [109] \\
\hline $\begin{array}{l}\text { Cylindrotheca } \\
\text { closterium }\end{array}$ & Fucoxanthin & $\begin{array}{l}\text { Microwave assisted extraction, vaccum microwave assisted } \\
\text { extraction and ultrasonic assisted extraction }\end{array}$ & $\begin{array}{l}\text { Extraction yield UAE: } 4.95 \pm 0.27 \mathrm{mg} / \mathrm{g} \text {; Rt soaking in acetone for } 60 \mathrm{~min}: 7.48 \pm 0.21 \\
\mathrm{mg} / \mathrm{g} \text {; hot soaking in acetone for } 30 \mathrm{~min}: 9.31 \pm 0.44 \mathrm{mg} / \mathrm{g} \text {; MAE: } 8.65 \pm 0.29 \mathrm{mg} / \mathrm{g} \text {; } \\
\text { VMAE (vacuum-microwave assisted extraction): } 5.25 \pm 0.04 \mathrm{mg} / \mathrm{g} \text { ) }\end{array}$ & [110] \\
\hline $\begin{array}{l}\text { Dunaliella } \\
\text { salina }\end{array}$ & Carotenoids (not specified) & Supercritical carbon dioxide & $\begin{array}{l}\text { highest carotenoids extraction yield ( } 115.43 \mathrm{mg} / \mathrm{g} \text { dry algae) was obtained at pressure of } \\
400 \text { bar and temperature of } 55^{\circ} \mathrm{C}\end{array}$ & [111] \\
\hline $\begin{array}{l}\text { Haematococcus } \\
\text { pluvialis }\end{array}$ & Astaxanthin & $\begin{array}{l}\text { Solvent extraction hydrochloric acid pretreatment followed } \\
\text { by acetone extraction (HCl-ACE), hexane/isopropanol (6 : } \\
4 \text {, v/v) mixture (HEX-IPA), methanol extraction followed by } \\
\text { acetone extraction (MET-ACE), and soy-oil extraction }\end{array}$ & HCl-ACE method yielded the highest astaxanthin content $(19.8 \pm 1.1 \%)$ & [112] \\
\hline
\end{tabular}


the electric field) [118]. Besides these factors, the temperature is another critical parameter affecting the efficacy of the electrotechnology assisted extraction [104]. Pulses of milliseconds (5 kV/cm- $40 \mathrm{~ms})$ or microseconds $(20 \mathrm{kV} / \mathrm{cm}$ $75 \mu \mathrm{s}$ ) have improved the efficiency of carotenoids extraction from Chlorella vulgaris by $80 \%$. In the microalgae Heterochlorella luteoviridis the application of MEF combined with ethanol as solvent $(180 \mathrm{~V}, 75 \mathrm{~mL} / 100 \mathrm{~mL}$ of ethanol solution) resulted in up to $73 \%$ of carotenoid extraction [119]. Moderate electric field (MEF) (0-180 V) has been evaluated as a pre-treatment for carotenoid extraction at different temperatures followed by extraction step using ethanol/water as solvent ( $75 \%$ of ethanol, v/v). The highest extraction yield, $86 \%$ of the total carotenoid content was achieved at both 40 and $50{ }^{\circ} \mathrm{C}$ with the MEF pretreatment [120]. HVED treatment has been applied and favored the selective recovery of intracellular compounds from algae Parachlorella kessleri and Nannochloropsis oculate [121, 122].

\subsection{Pressurized liquid extraction (PLE)}

The main purpose of using PLE is that it allows rapid extraction and reduces solvent consumption; therefore, it is sometimes referred to as accelerated solvent extraction. PLE involves the extraction using solvents at elevated temperature and pressure but always below their critical points. This normally falls in the ranges of 50$200{ }^{\circ} \mathrm{C}$ and $35-200$ bars. During PLE, the interaction between the solvent and the biological sample is increased compared to common solvent extraction methods. Therefore, less solvent is required for extraction. PLE has been applied for the extraction of carotenoids from freeze-dried microalgae and macroalgal biomass. In Phaeodactylum tricornutum pressurized liquid extractions resulted in exceptional amounts of fucoxanthin up to $26.1 \mathrm{mg} / \mathrm{g} \mathrm{dw}$ [123]. Pressurized liquid extraction has been successfully applied in the case of Neochloris oleoabundans for the recovery of bioactive carotenoids lutein, carotenoid monoesters and violaxanthin [124]. Pressurized liquid extraction (PLE) has been optimized for the extraction of carotenoids and chlorophylls from the green microalga Chlorella vulgaris and showed higher extraction efficiencies than maceration (MAC), soxhlet extraction (SOX), and ultrasound-assisted extraction (UAE) [49]. PLE has been optimized for Nannochloropsis oceanica with ethanol as extraction solvent. A total carotenoids content of $115.1 \pm 0.6 \mathrm{mg} / \mathrm{g}$ extract was obtained at the optimum extraction conditions of $57^{\circ} \mathrm{C}$ and 3 extraction cycles [125].

\subsection{Supercritical fluid extraction (SFE)}

SFE involves extraction using supercritical fluids i.e., fluids at a temperature and pressure above its critical limit. Supercritical fluids provide better solvating and transport properties than liquids due to their low viscosity and high diffusivity. For the selective extraction of a broad range of compounds, the solvating power of supercritical fluid can be adjusted by manipulating the temperature and pressure of the fluid. Carbon dioxide is the preferable solvent which can easily achieve supercritical conditions and has benefits like high purity, low toxicity and low flammability compared to other fluids. Supercritical carbon dioxide is non-polar and its polarity can be modified by using co-solvents. Besides $\mathrm{CO}_{2}$, ethane and ethylene are other SFE solvents that have been used for the extraction of carotenoids in some studies. In Scenedesmus obliquus the highest carotenoid yield was achieved at 250 bar and $60^{\circ} \mathrm{C}$ using SFE [126]. Supercritical $\mathrm{CO}_{2}$ extraction has been applied in Spirulina to obtain carotenoids, chlorophylls, and phycocyanins. The SFE method resulted in $3.5 \pm 0.2 \mathrm{mg} / \mathrm{g}$ total carotenoid contents in Spirulina [127].

\subsection{Subcritical fluid extraction}

Subcritical fluid extraction is similar to SFE, where subcritical (liquefied) fluids are used as extraction solvent. Subcritical fluid extraction works at relatively low temperature and pressure than supercritical fluid extraction. In various studies, subcritical $\mathrm{CO}_{2}, 1,1,1,2-$ tetrafluoroethane and dimethyl ether (DME) have shown the potential to extract carotenoids from algae. Subcritical fluid extraction has been performed to extract fucoxanthin from Phaeodactylum tricornutum. The highest fucoxanthin content $(0.69 \mathrm{mg} / \mathrm{g})$ was achieved with a solvent-to-solid ratio of $200: 1,20 \mathrm{MPa}, 35^{\circ} \mathrm{C}$ at $120 \mathrm{rpm} 60 \mathrm{~min}$ by subcritical extraction [128]. The carotenoids and chlorophyll-a from Laminaria japonica have been isolated using ethanol modified subcritical 1,1,1,2-tetrafluoroethane [129].

\subsection{High pressure homogenization (HPH) treatment} and enzyme-assisted extraction

Microalgal cells are difficult to disrupt, therefore, a physical or enzymatic pre-treatment before extraction can be opted to promote the recovery of carotenoids. Highpressure homogenization (HPH) is one such method, where, cell disruption is achieved by applying high intensity fluid stress (50-400 MPa). In comparison with other physical milling processes, it offers significant advantages such as ease of operation, commercial applicability, reproducibility and high throughput. High-pressure homogenization (HPH) found to be very effective in microalgae with a recalcitrant cell wall such as Nannochloropsis [130]. Cell disruption by high-pressure homogenization has been shown to increase carotenoid and $\omega 3$-LC-PUFA bio accessibility [131]. Enzyme-assisted extraction (EAE) methods use hydrolytic enzymes like cellulase and pectinase for improved extraction. Cellulase hydrolyzes the 1,4- $\beta$-d-glycosidic links of the cellulose, whereas, pectinase breaks down the pectic substances and pectin found in cell wall components. In a study, enzyme type (cellulase and pectinase), $\mathrm{pH}$ values, hydrolysis temperature, and time on the release of astaxanthin from Haematococcus pluvialis were evaluated. The results showed that enzymatic pre-treatment improve 
the separation yield of astaxanthin. Pectinase release rate of astaxanthin from $H$. pluvialis was found to be significantly higher than cellulase [132].

\section{Application of carotenoids}

Non-photosynthetic organisms (humans and animals) are unable to synthesize carotenoid. However, they intake them through their food metabolize them for normal physiological functions [133]. Carotenoid possess boundless and expansive applications and therefore have commercial significance. Further, health is paramount to the consumer, which triggers the large-scale production of these pigments. In this section application of different carotenoid is discussed along with their commercial implications.

\subsection{Astaxanthin}

Astaxanthin is generally known as 'Super Vit-E' due to its compelling antioxidant properties [134]. Kishimoto et al. [135] bestowed it with 'King of antioxidants' because of its better antioxidant properties as it emulates Vit C, resveratrol, CoQ10, green tea catechins, and Vit E. Lipid peroxidation, LDL oxidation, and peroxide-induced cytotoxicity, etc. are inhibited by astaxanthin [136]. Their roles as anti-inflammatory, hepatoprotector and protective influence on retinal, brain, and spinal cord neurons and in the prevention of cardiovascular disease have been reported [137]. Aquaculture feed; poultry and food industries use this tremendously as red colorant [138]. Astaxanthin favorably lowers the level of plasma reactive protein $\mathrm{C}$, down regulate inflammatory cytokines, modulate mitogen-induced lymphoproliferation, and boost the immune response [139]. It protects the skin from the detrimental effects of UV-A photo ageing and is therefore widely used in cosmetics [140]. The inability of astaxanthin to convert into Vit A in the human body safeguards from hypervitaminosis A toxicity even after its overconsumption [141].

\section{$6.2 \beta$-carotene}

The role of $\beta$-carotene as anti-inflammatory, antioxidant, immunoprotector, dermoprotector, hepatoprotecter, retinoprotective are well known [142]. The food colorant and cosmetic industries use this pigment on a large scale [143]. It has been reported that the beneficial role of this pigment in breast, colon, lung, liver, and skin cancers. $\beta$-carotene can trigger better functioning of gap junction intercellular communications and can diminish the harmful effect of $\mathrm{H}_{2} \mathrm{O}_{2}$ on the same and maintain the processes like cell differentiation, growth, and apoptosis [144]. Its regular consumption in the daily diet protects from night blindness and liver fibrosis.

\subsection{Fucoxanthin}

Fucoxanthin has well-marked use as antioxidant, anti-angiogenic, anti-inflammatory, photo- and neuroprotective, which makes it commercially valuable. Peng et al. [145] reported its role in hindering DNA damage and $\mathrm{H}_{2} \mathrm{O}_{2}$ induced apoptosis. In HL-60, PC-3, HT-29, DLD1 , and Caco-2 human cell lines it acts as an antiproliferative [146]. It reduces obesity by up-regulating uncoupling protein-1 (UCP 1) to speed up metabolism and energy expenditure [147]. Heo et al. [148] reported its role in reducing nitric oxide, prostaglandin, TNF- $\alpha$, histamine levels in in-vivo models.

\subsection{Zeaxanthin}

The role of zeaxanthin in ophthalmological fields is significant and crucial. It is naturally present in the central macula of the eye, and protects the visionary organ from blue, near UV radiations, age-related macular degeneration [149]. Its promising property as natural color mark it use in pigmentation of poultry and fishes, in food, and as an antioxidant in cosmetics [44]. Regular consumption of zeaxanthin might prove useful in avoiding lung and pancreatic cancers in diabetic patients and found to be effective in cardiovascular problems [150]. This xanthophyll has the ability to trigger apoptosis in melanoma cells and therefore useful in adjuvant therapy.

\subsection{Lycopene}

Lycopene has antioxidant, photo-protective properties. It proves to be anti-cancerous against cell lines from the human colon, breast, prostate, liver, and lymphocytes [151]. It prevents from early arthrosclerosis and high blood pressure problems by boosting endothelial functioning and lowering oxidative stress. Lycopene, also act as hypolipidemic in a way similar to statin and maintain blood cholesterol levels [152]. The sufficient daily doses of lycopene strengthen the skeleton system, enhance gap junction intercellular communications, and maintain glucose homeostasis, which in turn prevent type-2 diabetes. Viuda-Martos et al. [151] reported lycopene-induced inhibition of tumor metastasis because of modulated cell cycle progressions. The poultry farms use this as feed to improve the health of poultry birds and it also relieves heat stress in commercial poultry. Lycopene is commercially available in form of capsules, tablets, and in gel forms. It has profound role in cosmetics and coloring agent in food sectors.

\subsection{Lutein}

Marigold is the chief source of lutein production at the industrial level. Like zeaxanthin, it protects eye from pernicious UV, blue light and therefore, referred to as eye vitamin. It lowers the level of plasma factor D and in turn plays a defensive role against age-related macular degeneration and cataract. It is effectual as a chemotherapeutic agent [153]. It is an active anti-tumor substance against prostate, breast, and colon cancer. Lutein consumption can also lessen the chance of early atherosclerosis and lung cancer as well. It alleviates the effects of neurodegenerative disorders arise due to inflammation. It has prodigious use in poultry as yolk color enhancer, feather coloration through 
feed and as an additive in infant food, drug and cosmetics [154].

\subsection{Other pigments}

Canthaxanthin is a $\beta$-carotene derived product, is remarkably used in food and as an additive in animal feed to poultry and fish (salmon, rainbow trout). It is an FDA approved compound to be used as a fish color intensifier [44]. Its doses along with $\beta$-carotene prevent idiopathic photodermatosis. Capsanthin is another pigment that shows antioxidant activity and is used as a natural colorant in food and cosmetic. Nowadays, it has been widely used in chicken feed to intensify color of egg yolk. The food sector uses one more yellow-orange pigment i.e., Annatto, to provide color to meat products, beverages, and smoked seafood. Echineone is a by-product of astaxanthin, possess pro-vitamin A and antioxidant property. Another pigment, peridinin presents anti-carcinogenic activities. The neoxanthin might lessen the lung cancer risk through regular consumption of 9-(Z) neoxanthin [143].

\section{Global carotenoid market}

The global monetary value of carotenoids depends upon its demand by the consumer and its extraction cost. Major branches of the carotenoid market include feed, food, nutraceutical, pharmaceutical, cosmetic, and aquaculture sectors [154]. An amount of USD 1.5 billion market was expected at the global level but with compelling demand it is expected to surge to USD 2 billion by 2022 with a compound annual growth rate (CAGR) of 5.7\%. Astaxanthin, $\beta$-carotene, lutein, fucoxanthin, zeaxanthin dominate the market due to their wider applications. A report by BCC research mentions that capsanthin occupied a mammoth share of the total carotenoid market i.e., 285 million USD (19.7\%), followed by astaxanthin (18.5\%) of the total share, accounting 267.5 million USD, $\beta$-carotene-246.2 million USD (17\% of total), lutein totaled 225 million USD (15.6\%), annatto (Bixin)- 170 million USD (11.8\%), and lycopene at 107 million USD with (7.4\%) of total market [155]. The market value of astaxanthin is estimated to reach USD 426.9 million by 2022 from USD 288.7 million in 2017 at CAGR of 8.1\%. As per the estimations of Astaxanthin-Global Market Outlook (2017-2023), the global astaxanthin value is estimated to elevate from $\$ 615.19$ million in 2016 to $\$ 1226.14$ million by 2023 with a CAGR of $10.3 \%$. The utility of lutein will take the market value of pigment to 357.7 million USD by 2022 from 263.8 million USD in 2017 at CAGR of 6.3\% from 2017. The average market price of $\beta$-carotene is near to USD 300$1500 / \mathrm{kg}$ [156]. Capsanthin witnessed a monetary value of USD 300 million in 2017 (20\% of the total market) which will be projected to reach about 385 million USD by 2022 with CAGR of 5.1\%. Europe (Germany, France, Italy, Netherland, Spain) wrest the carotenoid market in terms of consumption followed by Asia and Pacific region (China and Japan) with the second largest consumption zone. Australia and New Zealand own the smallest market share in terms of consumption, while the Canadian market is unflagging with a declining CAGR (0.9\% in 2017 to $1.4 \%$ in 2019-2022). Brazil and Mexico govern the market in Latin America, Russia, Poland, Slovakia, and the Czech Republic are the growing markets of Eastern Europe [157].

There are several desperate elements and factors, which govern the carotenoid market. From production point of view, the revamping of the selected entity depends upon their cultural conditions i.e., temperature, irradiance, $\mathrm{pH}$, salinity, nutrients, and presence of oxidizing substances. Secondly, as consumers gaining interest and awareness to have an immune diet rather than muscle full supplement and balanced consumption is imperative in governing the carotenoid market and foster the overall demand and industrial production. The global carotenoid market estimates the major market value for the feed segment by 2023 because of less restricted regulations. Additionally, an increase in meat, poultry, and dairy products will accelerate the rise of the feed market. Feed segment is going to witness colossal demand because of a pandemic outbreak, animal diseases, and the requirement of quick-service restaurants both at the domestic and international level. The investment and participation of well-known cosmetic industries like Hindustan Unilever, L’Oreal, Henkel, and Beiersdorf may be lucrative for the growth of the European carotenoid market [9]. The high commercial demand and potential values inflate the market as per the demand and supply curve. Deficiency of raw material, efficient tools, and methods both for up streaming (extraction) and for the down streaming process (purification) attribute to high monetary value [158]. The presence of another compound along with required under amount substance make the large-scale production technically difficult and costly. Besides, legal and strict regulatory and approval checklist related to the health care issues, effect on environment and animals, constraint the market of carotenoids. The build-out of the carotenoid market and its constituent products depends on several ethical, social, commercial, and biotechnical factors. Biotechnologists are endeavouring for the burgeoning of production scale by developing green, renewable resources, efficacious technologies and companies are trying to propitiate consumers by sophisticated presentation and sale of their products. With the growing exigency for natural products and declining traditional resources, key commercial entities are investing in carotenoid production at a large scale and augmenting the carotenoid market competitiveness. The pre-eminent producers of carotenoid are listed in Table 3 along with their web address. 
Table 3. Major companies involved in carotenoid production at commercial level.

\begin{tabular}{|c|c|c|}
\hline S. No. & Name of company & Website address \\
\hline 1 & Algae technologies & https://www.algatech.com \\
\hline 2 & Mera pharmaceuticals & http://merapharma.com \\
\hline 3 & Cyanotech corporation & Cyanotech.com \\
\hline 4 & Valensa international & https://valensa.com \\
\hline 5 & Fuji chemical industries Co, Ltd. & ww.fujichemical.co.jp \\
\hline 6 & Nature beta technologies & www.nikken-miho.com \\
\hline 7 & AlgaNova international & http://www.algeanova.com \\
\hline 8 & Leili natutral products Co, Ltd. & www.leili.com \\
\hline 9 & Koninklijke DSM NV & www.dsm.com \\
\hline 10 & Sensient technologies corporation & https://www.sensient.com \\
\hline 11 & Market young & https://www.youngsmarket.com \\
\hline 12 & Novus international, Inc. & http://www.novusint.com \\
\hline 13 & Seambiotic & www.seambitotic.com \\
\hline 14 & Tanjin norland biotech Co, Ltd. & www.norlandbiotech.com \\
\hline 15 & Jingzhou natural astaxanthin Inc. & www.jzxqs.cn \\
\hline 16 & Nikken sohonsha corporation & www.nikken-miho.com \\
\hline 17 & Lycored Ltd. & https://www.lycored.com \\
\hline 18 & Divis laboratories & https://www.divislabs.com \\
\hline 19 & FMC corporation & www.fmc.com \\
\hline 20 & Naturex SA & https://www.naturex.com \\
\hline 21 & Kemin industries Inc. & https://www.kemin.com \\
\hline 22 & E.I.D parry Ltd. & https://www.eidparry.com \\
\hline 23 & Brenntag & https://wwwbrenntag.com \\
\hline 24 & D.D williamson and Co. Inc. & https://ddwcolor.com \\
\hline 25 & Dohler group & https://www.doehler.com \\
\hline 26 & ExcelVite SDN & https://www.excelvite.com \\
\hline 27 & Cognis nutrition and health & www.na.cognis.com \\
\hline 28 & Allied biotech & www.altratene.com \\
\hline 29 & BASF corporation & https://www.basf.com \\
\hline 30 & Omniactive & Omniactives.com \\
\hline 31 & Chrysantis & www.chrysantis.com \\
\hline
\end{tabular}

\section{Concluding remarks}

In this paper, the biosynthesis of carotenoids is discussed with special reference to algae. This discussion has brought to the notice that many genes are not yet characterized. A consensus pathway has been however drawn in this paper. This paper can be used as a framework to look in to the future research scope for more investigation into the carotenogenesis in algae. Molecular characterization of genes is essential for metabolic engineering of algae for enhanced production of carotenoids. Different extraction approaches revealed that a single method is not sufficient and different customized approaches are required for the extraction of different pigments. Increasing knowledge of the beneficial use of carotenoids has led to wider application and increase in the global market and there is still a huge potential for market growth in the future.

\section{Author contributions}

$\mathrm{AK}, \mathrm{VV}$ and $\mathrm{H}$ conceptualize this review article. AKG, KS, KM and MM wrote the original draft. PKB wrote and interpreted about chemistry of different carotenoids. AK, VV and $\mathrm{H}$ edited the manuscript and prepared the tables. All authors read and approved the final manuscript.

\section{Ethics approval and consent to participate}

Not applicable.

\section{Acknowledgment}

The authors are grateful Head, Department of Botany, Mohanlal Sukhadia University, Udaipur for providing necessary laboratory facility.

\section{Funding}

Part of this work is supported by a grant from the Department of Science and Technology, New Delhi (SERB File Number: EEQ/2020/000011). VV is thankful to DSTNanomission (Govt. of India) project number (SR/NM/NT1090/2014(G) for financial support.

\section{Conflict of interest}

The authors declare no conflicts of interest.

\section{References}

[1] Hou X, Rivers J, León P, McQuinn RP, Pogson BJ. Synthesis and function of apocarotenoid signals in plants. Trends in Plant Science. 2016; 21: 792-803.

[2] Cheng S, Khoo HE, Kong KW, Prasad KN, Galanakis CM. Extraction of carotenoids and applications. Carotenoids: Properties, Processing and Applications. 2020; 13: 259--288.

[3] Negro JJ, Garrido-Fernández J. Astaxanthin is the major carotenoid in tissues of white storks (Ciconia ciconia) feeding on introduced crayfish (Procambarus clarkii). Comparative Biochemistry and Physiology B. 2000; 126: 347-352.

[4] Tian B, Hua Y. Carotenoid biosynthesis in extremophilic Deinococcus-Thermus bacteria. Trends in Microbiology. 2010 18: 512-520.

[5] Slaný O, Klempová T, Marcinčák S, Čertík M. Production of high-value bioproducts enriched with $\gamma$-linolenic acid and $\beta$-carotene by filamentous fungi Umbelopsis isabellina using solid-state fermentations. Annals of Microbiology. 2020; 70: 5.

[6] Krause-Nehring J, Matthias Starck J, Palmer AR. Juvenile colour polymorphism in the red rock crab, Cancer productus: patterns, causes, and possible adaptive significance. Zoology. 2010; 113: 131-139.

[7] Honda M, Kageyama H, Hibino T, Ichihashi K, Takada W, Goto M. Isomerization of commercially important carotenoids (lycopene, $\beta$-Carotene, and astaxanthin) by natural catalysts: isothiocyanates and polysulfides. Journal of Agricultural and Food Chemistry. 2020; 68: 3228-3237. 
[8] Amorim-Carrilho KT, Cepeda A, Fente C, Regal P. Review of methods for analysis of carotenoids. TrAC Trends in Analytical Chemistry. 2014; 56: 49-73.

[9] Ambati RR, Gogisetty D, Aswathanarayana RG, Ravi S, Bikkina $\mathrm{PN}, \mathrm{Bo} \mathrm{L}$, et al. Industrial potential of carotenoid pigments from microalgae: current trends and future prospects. Critical Reviews in Food Science and Nutrition. 2019; 59: 1880-1902.

[10] Maoka T. Carotenoids as natural functional pigments. Journal of Natural Medicines. 2020; 74: 1-16.

[11] Farré G, Sanahuja G, Naqvi S, Bai C, Capell T, Zhu C, et al. Travel advice on the road to carotenoids in plants. Plant Science. 2010; 179: 28-48.

[12] Aoki H, Kieu NTM, Kuze N, Tomisaka K, Van Chuyen N. Carotenoid pigments in GAC fruit (momordica cochinchinensis SPRENG). Bioscience, Biotechnology, and Biochemistry. 2002; 66: 2479-2482.

[13] Sugiura M, Kato M, Matsumoto H, Nagao A, Yanoa M. Serum concentration of $\beta$-cryptoxanthin in Japan reflects the frequency of satsuma mandarin (Citrus unshiu Marc.) Consumption. Journal of Health Sciences. 2002; 48: 350-353.

[14] Sajilata MG, Singhal RS, Kamat MY. The carotenoid pigment zeaxanthin-a review. Comprehensive Reviews in Food Science and Food Safety. 2008; 7: 29-49.

[15] Priyadarshani AMB, Jansz ER. A critical review on carotenoid research in Sri Lankan context and its outcomes. Critical Reviews in Food Science and Nutrition. 2014; 54: 561-571.

[16] Bouvier F, Suire C, Mutterer J, Camara B. Oxidative remodeling of chromoplast carotenoids: identification of the carotenoid dioxygenase CsCCD and CsZCD genes involved in Crocus secondary metabolite biogenesis. The Plant Cell. 2003; 15: 47-62.

[17] Stanley L, Yuan Y. Transcriptional regulation of carotenoid biosynthesis in plants: so many regulators, so little consensus. Frontiers in Plant Science. 2019; 10: 1017.

[18] Takaichi S. Carotenoids in algae: distributions, biosyntheses and functions. Marine Drugs. 2011; 9: 1101-1118.

[19] Minhas AK, Hodgson P, Barrow CJ, Adholeya A. A review on the assessment of stress conditions for simultaneous production of microalgal lipids and carotenoids. Frontiers in Microbiology. 2016; 7: 546

[20] Sathasivam R, Radhakrishnan R, Kim JK, Park SU. An update on biosynthesis and regulation of carotenoids in plants. South African Journal of Botany. 2020. (in press)

[21] Sathasivam R, Ki J. A review of the biological activities of microalgal carotenoids and their potential use in healthcare and cosmetic industries. Marine Drugs. 2018; 16: 26.

[22] Neuman H, Galpaz N, Cunningham FX, Zamir D, Hirschberg J. The tomato mutationnxd1reveals a gene necessary for neoxanthin biosynthesis and demonstrates that violaxanthin is a sufficient precursor for abscisic acid biosynthesis. The Plant Journal. 2014; 78: 80-93.

[23] Collini E. Carotenoids in photosynthesis: the revenge of the "accessory” pigments. Chem. 2019; 5: 494-495.

[24] Gong M, Bassi A. Carotenoids from microalgae: a review of recent developments. Biotechnology Advances. 2016; 34: 13961412.

[25] Begum H, Yusoff FM, Banerjee S, Khatoon H, Shariff M. Availability and utilization of pigments from microalgae. Critical Reviews in Food Science and Nutrition. 2016; 56: 2209-2222.

[26] Avalos J, Carmen Limón M. Biological roles of fungal carotenoids. Current Genetics. 2015; 61: 309-324.

[27] Park H, Kreunen SS, Cuttriss AJ, DellaPenna D, Pogson BJ. Identification of the carotenoid isomerase provides insight into carotenoid biosynthesis, prolamellar body formation, and photomorphogenesis. The Plant Cell. 2002; 14: 321-332.

[28] Rodríguez-Villalón A, Gas E, Rodríguez-Concepción M. Colors in the dark. Plant Signaling \& Behavior. 2009; 4: 965-967.

[29] Cazzonelli CI, Pogson BJ. Source to sink: regulation of carotenoid biosynthesis in plants. Trends in Plant Science. 2010; 15: 266-274.
[30] Xie X, Yoneyama K, Yoneyama K. The strigolactone story. Annual Review of Phytopathology. 2010; 48: 93-117.

[31] Panis G, Carreon JR. Commercial astaxanthin production derived by green alga Haematococcus pluvialis: a microalgae process model and a techno-economic assessment all through production line. Algal Research. 2016; 18: 175-190.

[32] Singh J, Gu S. Commercialization potential of microalgae for biofuels production. Renewable and Sustainable Energy Reviews. 2010; 14: 2596-2610.

[33] Abe K, Hattori H, Hirano M. Accumulation and antioxidant activity of secondary carotenoids in the aerial microalga Coelastrella striolata var. multistriata. Food Chemistry. 2007; 100: 656-661.

[34] Bar E, Rise M, Vishkautsan M, Arad S. Pigment and structural changes in chlorella zofingiensis upon light and nitrogen stress. Journal of Plant Physiology. 1995; 146: 527-534.

[35] Chiu H, Liao J, Lu Y, Han Y, Shen Y, Venkatakrishnan K, et al. Anti-proliferative, anti-inflammatory and pro-apoptotic effects of Dunaliella salinaon human KB oral carcinoma cells. Journal of Food Biochemistry. 2017; 41: e12349.

[36] Aasen IM, Ertesvåg H, Heggeset TMB, Liu B, Brautaset T, Vadstein $\mathrm{O}$, et al. Thraustochytrids as production organisms for docosahexaenoic acid (DHA), squalene, and carotenoids. Applied Microbiology and Biotechnology. 2016; 100: 4309-4321.

[37] Koller M, Muhr A, Braunegg G. Microalgae as versatile cellular factories for valued products. Algal Research. 2014; 6: 52-63.

[38] Ishika T, Moheimani NR, Bahri PA, Laird DW, Blair S, Parlevliet D. Halo-adapted microalgae for fucoxanthin production: effect of incremental increase in salinity. Algal Research. 2019; 28: 66-73.

[39] Kim SM, Kang S, Kwon O, Chung D, Pan C. Fucoxanthin as a major carotenoid in Isochrysis aff. galbana: characterization of extraction for commercial application. Journal of the Korean Society for Applied Biological Chemistry. 2012; 55: 477-483.

[40] Xia S, Wang K, Wan L, Li A, Hu Q, Zhang C. Production, characterization, and antioxidant activity of fucoxanthin from the marine diatom Odontella aurita. Marine Drugs. 2013; 11: 26672681.

[41] Molina-Miras A, López-Rosales L, Sánchez-Mirón A, CerónGarcía MC, Seoane-Parra S, García-Camacho F, et al. Longterm culture of the marine dinoflagellate microalga Amphidinium carterae in an indoor LED-lighted raceway photobioreactor: production of carotenoids and fatty acids. Bioresource Technology. 2018; 265: 257-267.

[42] Assunção J, Guedes AC, Malcata FX. Biotechnological and pharmacological applications of biotoxins and other bioactive molecules from dinoflagellates. Marine Drugs. 2017; 15: 393.

[43] Nwachukwu ID, Udenigwe CC, Aluko RE. Lutein and zeaxanthin: production technology, bioavailability, mechanisms of action, visual function, and health claim status. Trends in Food Science \& Technology. 2016; 49: 74-84.

[44] Bhosale P, Bernstein PS. Microbial xanthophylls. Applied Microbiology and Biotechnology. 2005; 68: 445-455.

[45] Matos ÂP. The impact of microalgae in food science and technology. Journal of the American Oil Chemists' Society. 2017; 94: 1333-1350.

[46] Chacón-Lee TL, González-Mariño GE. Microalgae for "healthy" foods-possibilities and challenges. Comprehensive Reviews in Food Science and Food Safety. 2010; 9: 655-675.

[47] Sun Z, Li T, Zhou Z, Jiang Y. Microalgae as a source of lutein: chemistry, biosynthesis, and carotenogenesis. Advances in Biochemical Engineering/Biotechnology. 2016; 153: 37-58.

[48] Wu Z, Wu S, Shi X. Supercritical fluid extraction and determination of lutein in heterotrophically cultivated chlorella pyrenoidosa. Journal of Food Process Engineering. 2007; 30: 174-185.

[49] Cha KH, Lee HJ, Koo SY, Song D, Lee D, Pan C. Optimization of pressurized liquid extraction of carotenoids and chlorophylls from Chlorella vulgaris. Journal of Agricultural and Food Chemistry. 2010; 58: 793-797. 
[50] Gayathri S, Rajasree SRR, Kirubagaran R, Aranganathan L, Suman TY. Spectral characterization of $\beta$, $\varepsilon$-carotene-3, 3'-diol (lutein) from marine microalgae Chlorella salina. Renewable Energy. 2016; 98: 78-83.

[51] Del Campo JA, García-González M, Guerrero MG. Outdoor cultivation of microalgae for carotenoid production: current state and perspectives. Applied Microbiology and Biotechnology. 2007; 74: 1163-1174.

[52] Wang S, Zhang L, Chi S, Wang G, Wang X, Liu T, et al. Phylogenetic analyses of the genes involved in carotenoid biosynthesis in algae. Acta Oceanologica Sinica. 2018; 37: 89-101.

[53] Hirschberg J, Cohen M, Harker M, Lotan T, Mann V, Pecker I. Molecular genetics of the carotenoid biosynthesis pathway in plants and algae. Pure and Applied Chemistry. 1997; 69: 21512158.

[54] Nègre D, Aite M, Belcour A, Frioux C, Brillet-Guéguen L, Liu $\mathrm{X}$, et al. Genome-scale metabolic networks shed light on the carotenoid biosynthesis pathway in the brown algae saccharina japonica and cladosiphon okamuranus. Antioxidants. 2019; 8: 564

[55] Lohr M, Schwender J, Polle JEW. Isoprenoid biosynthesis in eukaryotic phototrophs: a spotlight on algae. Plant Science. 2012; 185-186: 9-22.

[56] Zhao L, Chang W, Xiao Y, Liu H, Liu P. Methylerythritol phosphate pathway of isoprenoid biosynthesis. Annual Review of Biochemistry. 2013; 82: 497-530.

[57] He Y, Ma Y, Du Y, Shen S. Differential gene expression for carotenoid biosynthesis in a green alga Ulva prolifera based on transcriptome analysis. BMC Genomics. 2018; 19: 916.

[58] Deng Y, Cheng L, Wang Q, Ge Z, Zheng H, Cao T, et al. Functional characterization of lycopene cyclases illustrates the metabolic pathway toward lutein in red algal seaweeds. Journal of Agricultural and Food Chemistry. 2020; 68: 1354-1363.

[59] Du Y, Guan J, Xu R, Liu X, Shen W, Ma Y, et al. Molecular cloning and expression analysis of the first two key genes through 2-C-methyl-D-erythritol 4-phosphate (MEP) pathway from Pyropia haitanensis (Bangiales, Rhodophyta). ALGAE. 2017; 32: 359-377.

[60] Lichtenthaler HK. The 1-deoxy-d-xylulose-5-phosphate pathway of isoprenoid biosynthesis in plants. Annual Review of Plant Physiology and Plant Molecular Biology. 1999; 50: 4765.

[61] Sapir-Mir M, Mett A, Belausov E, Tal-Meshulam S, Frydman A, Gidoni D, et al. Peroxisomal localization of Arabidopsis isopentenyl diphosphate isomerases suggests that part of the plant isoprenoid mevalonic acid pathway is compartmentalized to peroxisomes. Plant Physiology. 2008; 148: 1219-1228.

[62] Lange BM, Rujan T, Martin W, Croteau R. Isoprenoid biosynthesis: the evolution of two ancient and distinct pathways across genomes. Proceedings of the National Academy of Sciences of the United States of America. 2000; 97: 13172-13177.

[63] Rohmer M, Rohmer M. The discovery of a mevalonateindependent pathway for isoprenoid biosynthesis in bacteria, algae and higher plants. Natural Product Reports. 1999; 16: 565574.

[64] Wang J, Lei Y, Xiao Y, He X, Liang J, Jiang J, et al. Uncovering the functional residues of Arabidopsisisoprenoid biosynthesis enzyme HDS. Proceedings of the National Academy of Sciences. 2020; 117: 355-361.

[65] Sun T, Li L. Toward the 'golden' era: the status in uncovering the regulatory control of carotenoid accumulation in plants. Plant Science. 2020; 290: 110331.

[66] Ramos AA, Marques AR, Rodrigues M, Henriques N, Baumgartner A, Castilho R, et al. Molecular and functional characterization of a cDNA encoding 4-hydroxy-3-methylbut-2-enyl diphosphate reductase from Dunaliella salina. Journal of Plant Physiology. 2009; 166: 968-977.

[67] Lao YM, Jin H, Zhou J, Zhang HJ, Zhu XS, Cai ZH. A novel hydrolytic activity of Tri-functional geranylgeranyl pyrophosphate synthase in Haematococcus pluvialis. Plant \& Cell Physiology. 2018; 59: 2536-2548.

[68] Feng Y, Morgan RML, Fraser PD, Hellgardt K, Nixon PJ. Crystal structure of geranylgeranyl pyrophosphate synthase (crte) involved in cyanobacterial terpenoid biosynthesis. Frontiers in Plant Science. 2020; 11: 589.

[69] Ruiz-Sola MÁ, Coman D, Beck G, Barja MV, Colinas M, Graf A, et al. Arabidopsis geranylgeranyl diphosphate synthase 11 is a hub isozyme required for the production of most photosynthesisrelated isoprenoids. The New Phytologist. 2016; 209: 252-264.

[70] Yang L, Huang X, Lu Q, Zhu J, Lu S. Cloning and characterization of the geranylgeranyl diphosphate synthase (GGPS) responsible for carotenoid biosynthesis in Pyropia umbilicalis. Journal of Applied Phycology. 2016; 28: 671-678.

[71] Miras-Moreno B, Pedreño MÁ, Romero LA. Bioactivity and bioavailability of phytoene and strategies to improve its production. Phytochemistry Reviews. 2019; 18: 359-376.

[72] Tran D, Haven J, Qiu W, Polle JEW. An update on carotenoid biosynthesis in algae: phylogenetic evidence for the existence of two classes of phytoene synthase. Planta. 2009; 229: 723729.

[73] Wurtzel ET. Changing form and function through carotenoids and synthetic biology. Plant Physiology. 2019; 179: 830-843.

[74] García-Cerdán JG, Schmid EM, Takeuchi T, McRae I, McDonald KL, Yordduangjun N, et al. Chloroplast Sec14-like 1 (CPSFL1) is essential for normal chloroplast development and affects carotenoid accumulation in Chlamydomonas. Proceedings of the National Academy of Sciences. 2020; 117: 12452 12463.

[75] Mao X, Lao Y, Sun H, Li X, Yu J, Chen F. Time-resolved transcriptome analysis during transitions of sulfur nutritional status provides insight into triacylglycerol (TAG) and astaxanthin accumulation in the green alga Chromochloris zofingiensis. Biotechnology for Biofuels. 2020; 13: 128.

[76] Fang N, Wang C, Liu X, Zhao X, Liu Y, Liu X, et al. De novo synthesis of astaxanthin: from organisms to genes. Trends in Food Science \& Technology. 2019; 92: 162-171.

[77] Cui H, Wang Y, Qin S. Molecular evolution of lycopene cyclases involved in the formation of carotenoids in eukaryotic algae. Plant Molecular Biology Reporter. 2011; 29: 1013-1020.

[78] Inoue A, Iwayama T, Ojima T. Complementary DNA cloning and functional analysis of lycopene $\beta$-cyclase in the brown alga Undaria pinnatifida. Fisheries Science. 2019; 85: 717-729.

[79] Liang M, Zhu J, Jiang J. Carotenoids biosynthesis and cleavage related genes from bacteria to plants. Critical Reviews in Food Science and Nutrition. 2018; 58: 2314-2333.

[80] Sathasivam R, Ki J. Differential transcriptional responses of carotenoid biosynthesis genes in the marine green alga Tetraselmis suecica exposed to redox and non-redox active metals. Molecular Biology Reports. 2019; 46: 1167-1179.

[81] Yang L, Huang X, Hang Y, Deng Y, Lu Q, Lu S. The P450type carotene hydroxylase PuCHY1 from Porphyra suggests the evolution of carotenoid metabolism in red algae. Journal of Integrative Plant Biology. 2014; 56: 902-915.

[82] Liang M, Xie H, Chen H, Liang Z, Jiang J. Functional identification of two types of carotene hydroxylases from the green alga dunaliella bardawil rich in lutein. ACS Synthetic Biology. 2020; 9: 1246-1253.

[83] Dautermann O, Lohr M. A functional zeaxanthin epoxidase from red algae shedding light on the evolution of light-harvesting carotenoids and the xanthophyll cycle in photosynthetic eukaryotes. The Plant Journal. 2017; 92: 879-891.

[84] Goss R, Latowski D. Lipid dependence of xanthophyll cycling in higher plants and algae. Frontiers in Plant Science. 2020; 11 455.

[85] Dautermann O, Lyska D, Andersen-Ranberg J, Becker M, Fröhlich-Nowoisky J, Gartmann $\mathrm{H}$, et al. An algal enzyme required for biosynthesis of the most abundant marine carotenoids. Science Advances. 2020; 6: eaaw9183. 
[86] Moise AR, Al-Babili S, Wurtzel ET. Mechanistic aspects of carotenoid biosynthesis. Chemical Reviews. 2014; 114: 164193

[87] Edge R, McGarvey DJ, Truscott TG. The carotenoids as antioxidants-a review. Journal of Photochemistry and Photobiology. B, Biology. 1997; 41: 189-200.

[88] Polívka T, Sundström V. Ultrafast dynamics of carotenoid excited States-from solution to natural and artificial systems. Chemical Reviews. 2004; 104: 2021-2071.

[89] ZigmantasD, Hiller RG, Sharples FP, Frank HA, Sundström V, Polívka T. Effect of a conjugated carbonyl group on the photophysical properties of carotenoids. Physical Chemistry Chemical Physics. 2004; 6: 3009-3016.

[90] Fuciman M, Chábera P, Župčanová A, Hříbek P, Arellano JB, Vácha F, et al. Excited state properties of aryl carotenoids. Physical Chemistry Chemical Physics. 2010; 12: 3112.

[91] Frank HA, Josue JS, Bautista JA, van der Hoef I, Jansen FJ, Lugtenburg J, et al. Spectroscopic and photochemical properties of open-chain carotenoids. The Journal of Physical Chemistry B. 2002; 106: 2083-2092.

[92] Frigaard N, Bryant DA. Chlorosomes: antenna organelles in photosynthetic green bacteria. Microbiology Monographs. 2006; 16: 79-114.

[93] Graham JE, Lecomte JTJ, Bryant DA. Synechoxanthin, an aromatic c 40 xanthophyll that is a major carotenoid in the cyanobacterium synechococcus sp. PCC 7002. Journal of Natural Products. 2008; 71: 1647-1650.

[94] Winterhalter P, Rouseff R. Carotenoid-derived aroma compounds: an introduction. In Winterhalter O, Rouseff RL. (eds.) Carotenoid-derived aroma compounds. Washington, DC: American Chemical Society. 2001.

[95] Vogel JT, Tieman DM, Sims CA, Odabasi AZ, Clark DG, Klee HJ. Carotenoid content impacts flavor acceptability in tomato (Solanum lycopersicum). Journal of the Science of Food and Agriculture. 2010; 90: 2233-2240.

[96] Rolland N, Curien G, Finazzi G, Kuntz M, Maréchal E, Matringe $\mathrm{M}$, et al. The biosynthetic capacities of the plastids and integration between cytoplasmic and chloroplast processes. Annual Review of Genetics. 2012; 46: 233-264.

[97] Khoo KS, Chew KW, Yew GY, Manickam S, Ooi CW, Show PL. Integrated ultrasound-assisted liquid biphasic flotation for efficient extraction of astaxanthin from Haematococcus pluvialis. Ultrasonics Sonochemistry. 2020; 67: 105052.

[98] Fan Y, Niu Z, Xu C, Yang L, Chen F, Zhang H. Biocompatible protic ionic liquids-based microwave-assisted liquid-solid extraction of astaxanthin from Haematococcus pluvialis. Industrial Crops and Products. 2019; 141: 111809.

[99] Desai RK, Streefland M, Wijffels RH, Eppink MHM. Novel astaxanthin extraction from Haematococcus pluvialis using cell permeabilising ionic liquids. Green Chemistry. 2016; 18: 12611267.

[100] Nobre B, Marcelo F, Passos R, Beirão L, Palavra A, Gouveia L, et al. Supercritical carbon dioxide extraction of astaxanthin and other carotenoids from the microalga Haematococcus pluvialis. European Food Research and Technology. 2006; 223: 787-790.

[101] Sanzo GD, Mehariya S, Martino M, Larocca V, Casella P, Chianese $\mathrm{S}$, et al. Supercritical carbon dioxide extraction of astaxanthin, lutein, and fatty acids from haematococcus pluvialis microalgae. Marine Drugs. 2018; 16: 334.

[102] Molino A, Mehariya S, Iovine A, Larocca V, Di Sanzo G, Martino $\mathrm{M}$, et al. Extraction of astaxanthin and lutein from microalga haematococcus pluvialis in the red phase using $\mathrm{CO}_{2}$ supercritical fluid extraction technology with ethanol as co-solvent. Marine Drugs. 2018; 16: 432.

[103] Jaime L, Rodríguez-Meizoso I, Cifuentes A, Santoyo S, Suarez $\mathrm{S}$, Ibáñez E, et al. Pressurized liquids as an alternative process to antioxidant carotenoids' extraction from Haematococcus pluvialis microalgae. LWT—Food Science and Technology. 2010; 43: 105-112.
[104] Luengo E, Raso J. Pulsed electric field-assisted extraction of pigments from chlorella vulgaris. Handbook of Electroporation. 2017; 34: 2939-2954.

[105] Chen C, Jesisca, Hsieh C, Lee D, Chang C, Chang J. Production, extraction and stabilization of lutein from microalga Chlorella sorokiniana MB-1. Bioresource Technology. 2016; 200: 500-505.

[106] Chronopoulou L, Dal Bosco C, Di Caprio F, Prosini L, Gentili A, Pagnanelli F, et al. Extraction of carotenoids and fatsoluble vitamins from tetradesmus obliquus microalgae: an optimized approach by using supercritical CO2. Molecules. 2019; 24: 2581.

[107] Li H, Fan K, Chen F. Isolation and purification of canthaxanthin from the microalgaChlorella zofingiensis by high-speed counter-current chromatography. Journal of Separation Science. 2006; 29: 699-703.

[108] Kim SM, Jung Y, Kwon O, Cha KH, Um B, Chung D, et al. A potential commercial source of fucoxanthin extracted from the microalga Phaeodactylum tricornutum. Applied Biochemistry and Biotechnology. 2012; 166: 1843-1855.

[109] Zhang W, Wang F, Gao B, Huang L, Zhang C. An integrated biorefinery process: stepwise extraction of fucoxanthin, eicosapentaenoic acid and chrysolaminarin from the same Phaeodactylum tricornutum biomass. Algal Research. 2018; 32: 193200.

[110] Pasquet V, Chérouvrier J, Farhat F, Thiéry V, Piot J, Bérard J, et $a l$. Study on the microalgal pigments extraction process: Performance of microwave assisted extraction. Process Biochemistry. 2011; 46: 59-67.

[111] Pour Hosseini SR, Tavakoli O, Sarrafzadeh MH. Experimental optimization of SC-CO2 extraction of carotenoids from Dunaliella salina. The Journal of Supercritical Fluids. 2016; 121: 89-95.

[112] Dong S, Huang Y, Zhang R, Wang S, Liu Y. Four different methods comparison for extraction of astaxanthin from green alga Haematococcus pluvialis. The Scientific World Journal. 2014; 2014: 694305.

[113] Kapoore RV, Butler TO, Pandhal J, Vaidyanathan S. Microwave-assisted extraction for microalgae: from biofuels to biorefinery. Biology. 2018; 7: 18.

[114] Fabrowska J, Messyasz B, Szyling J, Walkowiak J, Łęska B. Isolation of chlorophylls and carotenoids from freshwater algae using different extraction methods. Phycological Research. 2018; 66: 52-57.

[115] Zhao L, Chen G, Zhao G, Hu X. Optimization of microwaveassisted extraction of astaxanthin from haematococcus pluvialis by response surface methodology and antioxidant activities of the extracts. Separation Science and Technology. 2009; 44: 243262.

[116] Bachchhav MB, Kulkarni MV, Ingale AG. Process-intensified extraction of phycocyanin followed by $\beta$-carotene from Spirulina platensis using ultrasound-assisted extraction. Separation Science and Technology. 2020; 55: 932-944.

[117] Şahin S, Mohd Nasir NT, Erken İ, Elibol Çakmak Z, Cakmak T. Antioxidant composite films with chitosan and carotenoid extract from Chlorella vulgaris: optimization of ultrasonic-assisted extraction of carotenoids and surface characterization of chitosan films. Materials Research Express. 2019; 6: 095404.

[118] Poojary MM, Barba FJ, Aliakbarian B, Donsì F, Pataro G, Dias DA, et al. Innovative alternative technologies to extract carotenoids from microalgae and seaweeds. Marine Drugs. 2016; 14: 214.

[119] Jaeschke DP, Menegol T, Rech R, Mercali GD, Marczak LDF. Carotenoid and lipid extraction from Heterochlorella luteoviridis using moderate electric field and ethanol. Process Biochemistry. 2016; 51: 1636-1643.

[120] Jaeschke DP, Merlo EA, Mercali GD, Rech R, Marczak LDF. The effect of temperature and moderate electric field pre-treatment on carotenoid extraction from Heterochlorella lu- 
teoviridis. International Journal of Food Science \& Technology. 2019; 54: 396-402.

[121] Zhang R, Grimi N, Marchal L, Vorobiev E. Application of high-voltage electrical discharges and high-pressure homogenization for recovery of intracellular compounds from microalgae Parachlorella kessleri. Bioprocess and Biosystems Engineering. 2019; 42: 29-36.

[122] Zhang R, Marchal L, Lebovka N, Vorobiev E, Grimi N. Twostep procedure for selective recovery of bio-molecules from microalga Nannochloropsis oculata assisted by high voltage electrical discharges. Bioresource Technology. 2020; 302: 122893.

[123] Derwenskus F, Metz F, Gille A, Schmid-Staiger U, Briviba K, Schließmann U, et al. Pressurized extraction of unsaturated fatty acids and carotenoids from wet $\mathrm{C}$. vulgaris and P. tricornutum biomass using subcritical liquids. GCB Bioenergy. 2018.

[124] Castro-Puyana M, Pérez-Sánchez A, Valdés A, Ibrahim OHM, Suarez-Álvarez S, Ferragut JA, et al. Pressurized liquid extraction of Neochloris oleoabundans for the recovery of bioactive carotenoids with anti-proliferative activity against human colon cancer cells. Food Research International. 2017; 99: 1048-1055.

[125] Gallego R, Bueno M, Chourio AM, Ibáñez E, Saldaña MDA, Herrero M. Use of high and ultra-high pressure based-processes for the effective recovery of bioactive compounds from Nannochloropsis oceanica microalgae. The Journal of Supercritical Fluids. 2021; 167: 105039.

[126] Guedes AC, Gião MS, Matias AA, Nunes AVM, Pintado ME, Duarte CMM, et al. Supercritical fluid extraction of carotenoids and chlorophylls a, b and c, from a wild strain of Scenedesmus obliquus for use in food processing. Journal of Food Engineering. 2013; 116: 478-482.

[127] Marzorati S, Schievano A, Idà A, Verotta L. Carotenoids, chlorophylls and phycocyanin from Spirulina: supercritical CO2 and water extraction methods for added value products cascade. Green Chemistry. 2020; 22: 187-196.

[128] Aslanbay Guler B, Deniz I, Demirel Z, Yesil-Celiktas O, Imamoglu E. A novel subcritical fucoxanthin extraction with a biorefinery approach. Biochemical Engineering Journal. 2020; 153: 107403

[129] Lu J, Feng X, Han Y, Xue C. Optimization of subcritical fluid extraction of carotenoids and chlorophyll a from Laminaria japonica Aresch by response surface methodology. Journal of the Science of Food and Agriculture. 2014; 94: 139-145.

[130] Shene C, Monsalve MT, Vergara D, Lienqueo ME, Rubilar M. High pressure homogenization of Nannochloropsis oculatafor the extraction of intracellular components: effect of process conditions and culture age. European Journal of Lipid Science and Technology. 2016; 118: 631-639.

[131] Bernaerts T, Verstreken H, Dejonghe C, Gheysen L, Foubert I, et al. Cell disruption of Nannochloropsis sp. improves in vitro bioaccessibility of carotenoids and $\omega 3$-LC-PUFA. Journal of Functional Foods. 2020; 65: 103770.

[132] Zhao X, Zhang X, Liu H, Zhu H, Zhu Y. Enzyme-assisted extraction of astaxanthin from Haematococcus pluvialis and its stability and antioxidant activity. Food Science and Biotechnology. 2019; 28: 1637-1647.

[133] Berendschot TTJM, Plat J. Plant stanol and sterol esters and macular pigment optical density. Handbook of Nutrition, Diet and the Eye. 2014; 18: 441-449.

[134] Murillo AG, DiMarco DM, Fernandez ML. The potential of non-provitamin a carotenoids for the prevention and treatment of non-alcoholic fatty liver disease. Biology. 2016; 5: 42.

[135] Kishimoto Y, Yoshida H, Kondo K. Potential antiatherosclerotic properties of astaxanthin. Marine Drugs. 2016; 14

[136] Ambati RR, Phang SM, Ravi S, Aswathanarayana RG. Astaxanthin: sources, extraction, stability, biological activities and its commercial applications-a review. Marine Drugs. 2014; 12 128-152.
[137] Monroy-Ruiz J, Sevilla M, Carrón R, Montero M. Astaxanthinenriched-diet reduces blood pressure and improves cardiovascular parameters in spontaneously hypertensive rats. Pharmacological Research. 2011; 63: 44-50.

[138] Buono S, Langellotti AL, Martello A, Rinna F, Fogliano V. Functional ingredients from microalgae. Food \& Function. 2014; 5: 1669-1685.

[139] Yuan J, Peng J, Yin K, Wang J. Potential health-promoting effects of astaxanthin: a high-value carotenoid mostly from microalgae. Molecular Nutrition \& Food Research. 2011; 55: 150 165.

[140] Suganuma K, Nakajima H, Ohtsuki M, Imokawa G. Astaxanthin attenuates the UVA-induced up-regulation of matrixmetalloproteinase-1 and skin fibroblast elastase in human dermal fibroblasts. Journal of Dermatological Science. 2010; 58 136-142.

[141] Fassett RG, Coombes JS. Astaxanthin: a potential therapeutic agent in cardiovascular disease. Marine Drugs. 2011; 9: 447_ 465.

[142] Chidambara Murthy KN, Vanitha A, Rajesha J, Mahadeva Swamy M, Sowmya PR, Ravishankar GA. In vivo antioxidant activity of carotenoids from Dunaliella salin-a green microalga. Life Sciences. 2005; 76: 1381-1390.

[143] Saini RK, Moon SH, Gansukh E, Keum Y. An efficient one-step scheme for the purification of major xanthophyl carotenoids from lettuce, and assessment of their comparative anticancer potential. Food Chemistry. 2018; 266: 56-65.

[144] Kim J, Lee W, Rhee HC, Kim S. Red paprika (Capsicum annuum L.) and its main carotenoids, capsanthin and $\beta$-carotene, prevent hydrogen peroxide-induced inhibition of gap-junction intercellular communication. Chemico-Biological Interactions. 2016; 254: 146-155.

[145] Peng J, Yuan JP, Wu CF, Wang JH.Fucoxanthin, a marine carotenoid present in brown seaweeds and diatoms: metabolism and bioactivities relevant to human health. Marine Drugs. 2011; 9: $1806-1828$.

[146] Hosokawa M, Wanezaki S, Miyauchi K, Kurihara H, Kohno H, Kawabata J, et al. Apoptosis-inducing effect of fucoxanthin on human leukemia cell line HL-60. Food Science and Technology Research. 1999; 5: 243-246.

[147] Maeda H, Hosokawa M, Sashima T, Funayama K, Miyashita K. Fucoxanthin from edible seaweed, Undaria pinnatifida, shows antiobesity effect through UCP1 expression in white adipose tissues. Biochemical and Biophysical Research Communications. 2005; 332: 392-397.

[148] Heo S, Ko S, Kang S, Kang H, Kim J, Kim S, et al. Cytoprotective effect of fucoxanthin isolated from brown algae Sargassum siliquastrum against H2O2-induced cell damage. European Food Research and Technology. 2008; 228: 145-151.

[149] Landrum JT, Bone RA. Lutein, zeaxanthin, and the macular pigment. Archives of Biochemistry and Biophysics. 2001; 385: 28-40.

[150] Jansen RJ, Robinson DP, Stolzenberg-Solomon RZ, Bamlet WR, de Andrade M, Oberg AL, et al. Nutrients from fruit and vegetable consumption reduce the risk of pancreatic cancer. Journal of Gastrointestinal Cancer. 2013; 44: 152-161.

[151] Viuda-Martos M, Sanchez-Zapata E, Sayas-Barberá E, Sendra E, Pérez-Álvarez JA, Fernández-López J. Tomato and tomato byproducts. Human health benefits of lycopene and its application to meat products: a review. Critical Reviews in Food Science and Nutrition. 2014; 54: 1032-1049.

[152] Sultan Alvi S, Ansari IA, Khan I, Iqbal J, Khan MS. Potential role of lycopene in targeting proprotein convertase subtilisin/kexin type-9 to combat hypercholesterolemia. Free Radical Biology \& Medicine. 2017; 108: 394-403.

[153] Gong X, Smith JR, Swanson HM, Rubin LP. Carotenoid lutein selectively inhibits breast cancer cell growth and potentiates the effect of chemotherapeutic agents through ros-mediated mechanisms. Molecules. 2018; 23: 905. 
[154] Lin J, Lee D, Chang J. Lutein production from biomass: marigold flowers versus microalgae. Bioresource Technology. 2015; 184: 421-428.

[155] Anonymous. The Global Market for Carotenoids. 2018. Available at: https://www.bccresearch.com/market-research/fo od-and-beverage/the-global-market-for-carotenoids.html (Accessed: 3 December 2020).

[156] Yaakob Z, Ali E, Zainal A, Mohamad M, Takriff MS. An overview: biomolecules from microalgae for animal feed and aquaculture. Journal of Biological Research. 2014; 21: 6.

[157] Bogacz-Radomska L, Harasym J, Piwowar A. Commercialization aspects of carotenoids. Carotenoids: Properties, Processing and Applications. 2020; 114: 327-357.

[158] Ventura SPM, Nobre BP, Ertekin F, Garcia-Vaquero M, Viera $\mathrm{F}$, Koc M, et al. Extraction of value added compounds from microalgae. In Microalgae-based biofuels and bioproducts (pp. 461-483). Woodhead Publishing. 2017.

Abbreviations: AACT, acetoacetyl-CoA thiolase; ABA, abscisic acid; $\mathrm{BCH}, \beta$-carotene hydroxylase; BKT, $\beta$ carotene ketolase; CAGR, Compound annual growth rate; CMK, 4- (cytidine 5'-diphospho)-2-C-methyl-D-erythritol kinase; Crt-ISO, carotenoid isomerase; DMAPP, dimethylallyl diphosphate; DXP, 1-deoxy-D-xylulose 5-phosphate; DXR, 1-deoxy-D-xylulose-5-phosphate reductoisomeras; DXS, 1-deoxy-D-xylulose-5-phosphate synthase; EHY, عcarotene hydroxylase; ESTs, expressed sequence tags; FPPS, farnesyl diphosphate synthase; GGPP, geranyl geranyl pyrophosphate; GGPPS, geranylgeranyl diphosphate synthase; GPPS, geranyl diphosphate synthase; GSMN, genome scale metabolic network; HDR, 4-hydroxy-3- methylbut-2-enyl diphosphate reductase; HDS, 4-hydroxy3-methylbut-2-enyl diphosphate synthase; HMG-CoA, $\beta$-Hydroxy $\beta$-methylglutaryl-CoA; HMGR, 3-hydroxy3-methylglutaryl-CoA reductase; HMGS, 3-hydroxy-3methylglutaryl-CoA synthase; IDI, isopentenyl diphosphate isomerase; IPP, isopentenyl diphosphate; LCYB, lycopene $\beta$-cyclase; LCYE, lycopene $\varepsilon$-cyclase; MCT, 2C-methyl-D-erythritol 4-phosphate cytidylyl transferase; MDS, 2-C-methyl-D-erythritol 2,4- cyclodiphosphate synthase; MEP, methyl erythritol phosphate; MVA, mevalonate; MVD, mevalonate diphosphate decarboxylase; MVK, mevalonate kinase; NXS, neoxanthin synthase; PDS, phytoene desaturase; PMK, phosphomevalonate kinase; PSY, phytoene synthase; SL, strigolactone; VDE, violaxanthin de-epoxidase; ZDS, ろ-carotene desaturase; ZEP, zeaxanthin epoxidase; Z-ISO, $\zeta$-carotene isomerase.

Keywords: Astaxanthin; Biosynthesis; Carotene; Fucoxanthin; High-Value compounds

Send correspondence to: Harish, Department of Botany, Mohanlal Sukhadia University, 313001 Udaipur, Rajasthan, India, E-mail: harish.botany1979@gmail.com

Ashwani Kumar, Metagenomics and Secretomics Research Laboratory, Department of Botany, Dr. Harisingh Gour Central University, 470003 Sagar, MP, India, E-mail: ashwaniiitd@hotmail.com 